Non-linear finite-element analysis of the shear response in prestressed

concrete bridges

H. Broo, M. Plos, K. Lundgren and B. Engström

Published in Magazine of Concrete Research, see journal homepage http://www.icevirtuallibrary.com/content/journals

"Permission is granted by ICE Publishing to print one copy for personal use. Any other use of these PDF files is subject to reprint fees." 


\title{
Non-linear finite-element analysis of the shear response in prestressed concrete bridges
}

\author{
H. Broo, M. Plos, K. Lundgren and B. Engström \\ Chalmers University of Technology
}

\begin{abstract}
For the structural assessment of concrete bridges, the non-linear finite-element method has become an important and increasingly used tool. The method has shown a great potential to reveal higher load-carrying capacity compared with conventional assessment methods. However, the modelling method used for reinforced and prestressed concrete members subjected to shear and torsion has been questioned. The aim of this study is to present an analysis method for evaluation of the load-carrying capacity of prestressed concrete bridges, when failure resulting from shear and torsion is the main problem. The modelling method used was previously worked out and verified for shear-type cracking and shear failure. Here, shell elements with embedded reinforcement were used together with non-linear material models, taking into account the fracture energy of cracking plain concrete and the reduction of the concrete compression strength owing to lateral tensile strain. Analyses with the method proposed have shown to predict the shear response and the shear capacity on the safe side. In the work presented here, the load-carrying capacity of a box-girder bridge was evaluated as a case study. The whole bridge was modelled, but only the part that was most critical to shear and torsion was modelled according to the method previously worked out and was combined with beam elements for the rest of the bridge. The case study showed a substantially higher load-carrying capacity for the bridge compared with the assessment with conventional methods. In the evaluation, several possible safety formats were used in combination with the non-linear finite-element method. It was shown that the format using partial safety factors gave unrealistic conservative results; it is more correct to use the semi-probabilistic formats for non-linear finite-element analysis.
\end{abstract}

\section{Notation}

$A_{\mathrm{c}} \quad$ concrete area: $\mathrm{m}^{2}$

$B \quad$ bogie load of type vehicle: $\mathrm{N}$

$E_{\mathrm{c}} \quad$ modulus of elasticity of concrete: $\mathrm{Pa}$

$E_{\mathrm{p}} \quad$ modulus of elasticity of prestressing steel: $\mathrm{Pa}$

$E_{\mathrm{s}} \quad$ modulus of elasticity of reinforcing steel: $\mathrm{Pa}$

$f_{\mathrm{cc}} \quad$ concrete compressive strength: $\mathrm{Pa}$

$f_{\text {ct }} \quad$ concrete tensile strength: $\mathrm{Pa}$

$f_{\mathrm{d}} \quad$ design strength: $\mathrm{Pa}$

$f_{\mathrm{k}} \quad$ characteristic strength: $\mathrm{Pa}$

$f_{\mathrm{m}} \quad$ mean strength: $\mathrm{Pa}$

$f_{\mathrm{p}} \quad$ tensile strength of prestressing steel: $\mathrm{Pa}$

$f_{\mathrm{u}} \quad$ ultimate strength of reinforcing or prestressing steel: $\mathrm{Pa}$ $f_{\mathrm{y}} \quad$ yield strength of reinforcement: $\mathrm{Pa}$

$G_{\mathrm{f}} \quad$ concrete fracture energy: N/m

$h \quad$ characteristic length: $\mathrm{m}$

$P$ force: $\mathrm{N}$

$R_{\mathrm{d}} \quad$ design resistance: $\mathrm{N}$

$R_{\mathrm{k}} \quad$ characteristic resistance: $\mathrm{N}$

$R_{\mathrm{m}} \quad$ mean resistance: $\mathrm{N}$

$s_{\mathrm{m}} \quad$ mean crack spacing: $\mathrm{m}$

$\alpha \quad$ sensitivity factor

$\beta \quad$ reliability index

$\gamma_{0} \quad$ global safety factor

$\gamma_{\mathrm{c}} \quad$ partial safety factor for concrete

$\gamma_{\mathrm{m}} \quad$ partial safety factor material

$\gamma_{\mathrm{n}} \quad$ partial safety factor for action

$\gamma_{\mathrm{s}} \quad$ partial factor for reinforcing or prestressing steel

average principal tensile strain

average principal compressive strain

ultimate crack strain

dynamic multiplication factor

reinforcement amount

principal tensile stress: $\mathrm{Pa}$ 
$\sigma_{3} \quad$ principal compressive stress: $\mathrm{Pa}$

$\phi \quad$ diameter or reinforcement bar: $m$

\section{Introduction}

Large investments have been made in infrastructure, and the present stock of bridges represents a huge asset for society. Therefore, maintenance and upgrading of bridges are very important. Since most concrete bridges were designed and constructed, the traffic loads have increased and many bridges are subjected to higher loads than originally designed for. In the future, it is likely that the traffic load demands will further increase. The bridges' condition has also deteriorated owing to the environment or accidents. Hence, it is important to be able to upgrade the existing bridges and to ensure that they perform properly under the increased loads with respect to their actual condition. Today, many bridges are strengthened or replaced because their reliability cannot be guaranteed based on the structural assessments made. Large savings, both economic and environmental, would be possible if more correct and reliable assessments were made.

The principal aims of design and assessment of concrete bridges are the same: to demonstrate that the bridge has the required load-carrying capacity and performance under service conditions. However, in design, there are large uncertainties in the overall behaviour, the material properties and the loads, and a conservative design can be made without great cost. In assessment of existing bridges, some of the uncertainties can be reduced by measurements, testing and monitoring. A too conservative assessment may give a misapprehension that the requirements are unfulfilled, with unnecessary strengthening or demolition as a consequence. Therefore, it is important to predict the load-carrying capacity as appropriately as possible by using more enhanced assessment methods. There are several advanced methods suitable for bridge design or assessment; see for example Mokhtar and Ghail, ${ }^{1}$ Shushkewich, ${ }^{2}$ Picard and Massicotte, ${ }^{3}$ Shushkewich ${ }^{4}$ and Sustainable Bridges. ${ }^{5}$

Advanced simulations by means of non-linear finiteelement (FE) analysis of concrete structures are now well established for research within structural engineering. It is also increasingly used in engineering practice for assessment of existing concrete bridges. An overview of structural assessment of bridges with the finiteelement method (FEM) is presented in Sustainable Bridges. ${ }^{5}$ The number of references within the area is rather limited: Huria et al., ${ }^{6}$ Chowdhury and Ray, ${ }^{7}$ Shahrooz et al., ${ }^{8}$ Ho and Shahrooz ${ }^{9}$ and Song et al. ${ }^{10}$ The assessments made by Plos, ${ }^{11}$ and Plos and Gylltoft $^{12,13}$ have shown a great potential to reveal higher load-carrying capacities compared with conventional assessment methods. It is also stated in Sustainable Bridges ${ }^{5}$ that non-linear analysis is the analysis method with the highest potential for discovering any additional sources for load-carrying capacity of concrete bridges. Non-linear analysis gives the possibility to resemble the redistribution of sectional forces in statically undetermined structures. Also the redistribution of internal stresses can be simulated by including the fracture energy associated with cracking concrete. Both govern the higher load-carrying capacity shown. The structural effects utilised to achieve a higher capacity for previously assessed bridges have mainly been associated with bending moment and normal forces.

Plos and Gylltoft ${ }^{13}$ have also shown a higher loadcarrying capacity for a bridge where shear and torsion governed the failure. However, the modelling method used in these FE analyses was not verified and the results were brought into question. Non-linear FE analyses of concrete members with vertical shear reinforcement subjected to shear have been reported by several researchers, for example Ayoub and Filippou, ${ }^{14}$ Yamamoto and Vecchio, ${ }^{15}$ Vecchio and Shim ${ }^{16}$ and Kettil et al. ${ }^{17}$ These analyses were made to verify established material models or developed FE programs. A commercial FE program, usable by engineers in daily practice, has not been adopted. Therefore, in a previous study by the current authors, tests of shear panels and beams were analysed with such a non-linear FE program to examine the reliability of the methods and to develop a verified methodology that gives a lower bound value of the load-carrying capacity in cases of shear and torsion; see Broo et al. ${ }^{18}$ To evaluate the proposed methodology further, and to verify its applicability and reliability for assessment of bridges, the load-carrying capacity of a prestressed concrete box girder bridge was evaluated in a case study and is presented in the current paper.

The aim of this study is to show how the modelling method, worked out in Broo et al., ${ }^{18}$ can be used for assessment of a prestressed concrete bridge subjected to shear and torsion. The objective was not only to evaluate the load-carrying capacity but also to follow the response and to estimate the failure mode. Engineers using commercial non-linear FE programs, not particularly designed for shear analysis, should be able to use the method in their daily practice. The Källösund Bridge, used for the case study, has previously been evaluated by Plos and Gylltoft. ${ }^{13}$ The evaluation presented here was, compared with the previous one, improved in several respects. For instance, the modelling method used has been verified, the final loading was made in a deformation-controlled process, and longterm effects such as creep were taken into account.

A general problem when using non-linear FE analysis for structural assessment is how to determine the reliability of the load-carrying capacity. Possible alternative safety formats suitable for non-linear analysis are presented in EN 1992-2, ${ }^{19}$ in Sustainable Bridges ${ }^{5}$ and by Cervenka et $a l^{20}$ In this study semiprobabilistic formats according to Sustainable Bridges ${ }^{5}$ were used and compared with deterministic formats. 


\section{Structural assessment of the shear response in concrete bridges}

\section{Shear response and shear failure}

Both shear forces and torsional moments cause shear stresses that can result in cracks in a concrete member. Cracks owing to shear stresses are usually inclined relative to the direction of the reinforcement. To satisfy the new equilibrium after shear cracking, longitudinal reinforcement and transverse reinforcement or friction in the crack are required. The visual shear cracks are preceded by the formation of micro-cracks. The microcracking and the following crack formation change the stiffness relations in the member, and a redistribution of stresses can occur resulting in strut inclinations smaller than $45^{\circ}$; see Hegger et al. ${ }^{21}$ Owing to the rotation of the struts, more transverse reinforcement can be activated. This behaviour becomes more pronounced when the transverse reinforcement starts to yield. The rotation of the compressive struts can continue until failure. Possible failure modes in shear are (a) sliding along a shear crack and $(b)$ crushing of the concrete between two shear cracks. In the case of transverse reinforcement, shear sliding cannot take place before the transverse reinforcement yields. An important objective of shear and torsion design, in addition to providing the required load-carrying capacity, is to avoid a sudden failure of the structural member. It is also necessary to predict the behaviour in the serviceability limit state (SLS) - that is, deformations and crack widths under service load conditions.

\section{Structural assessment}

The objective of a structural assessment of an existing bridge is to assess whether the requirements of serviceability and load-carrying capacity are fulfilled with sufficient reliability. Assessment of a bridge usually means to determine, by calculations, a theoretical value of the axle load A and bogie load B for a type vehicle (see for example Vägverket ${ }^{22}$ ) that the bridge can resist. The assessment can also be used to determine regions with insufficient load-carrying capacities, as a basis for design of strengthening.

Sustainable Bridges ${ }^{5}$ presents an assessment strategy for enhanced evaluation of load-carrying capacity of existing bridges. The assessment of an existing bridge is preferably made by using analysis methods on different levels with increasing accuracy and complexity. In an initial assessment, a linear analysis of the structural system is usually made to determine cross-sectional forces and moments. In this analysis, all possible load combinations, type vehicles and traffic load positions are evaluated. For each cross-section the maximum cross-sectional forces are presented and the resistance of the cross-section is calculated with conventional design methods.

Design and assessment for shear and torsion are currently still commonly made by using simplified ana- lytical or empirical design methods. For members with shear reinforcement these are based on the truss model; see Figure 1. It is well known that, for shear-reinforced concrete members, the shear capacity is larger than what can be explained by the reinforcement contribution determined from a truss model. The truss model can be combined with a concrete contribution, compensating for the difference in shear capacity found in tests and theoretically calculated capacities. The concrete contribution is empirical, but accounts for the shear transferred in the compression zone and across the crack. The influencing parameters are the softening of cracking concrete, the bond between reinforcement and concrete, the aggregate interlocking in the crack, and the dowel action provided by the reinforcement; see Figure 1. The methods based on the truss model are only valid in the ultimate limit state (ULS) - that is, they can only predict the ultimate shear capacity.

To predict also the shear response, more enhanced methods are needed, such as the modified compression field theory (MCFT) of Vecchio and Collins, ${ }^{23}$ or the softened-truss models of Pang and Hsu. ${ }^{24,25}$ These methods are based on a smeared approach - that is, the influences of cracks are smeared over a region and the calculations are made with average stresses and average

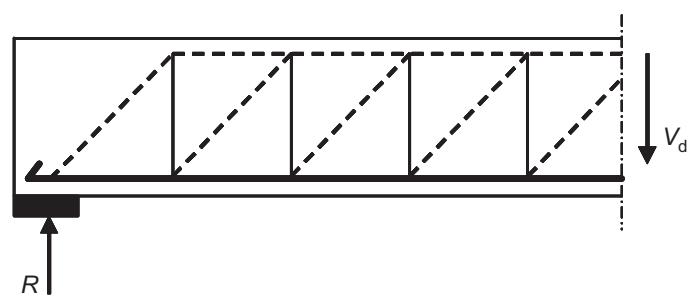

(a)

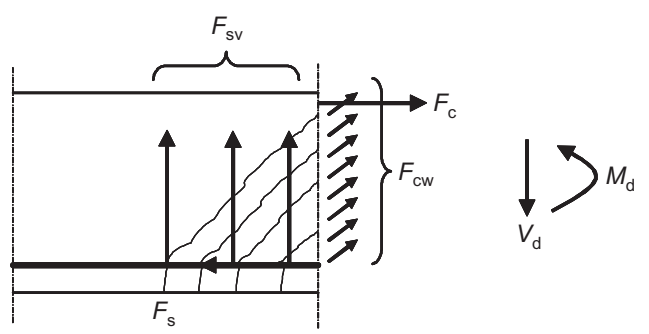

(b)

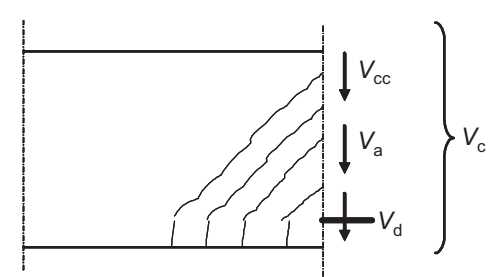

(c)

Figure 1. Models describing the transition of shear force after cracking. (a) and (b) The truss model. (c) The concrete contribution term $V_{c}$ is empirical but accounts for the shear transferred in the compression zone and in the crack: the softening of cracking concrete, the tension stiffening, the aggregate interlocking and dowel action 
strains. Stress equilibrium, strain compatibility and constitutive laws are used to predict the shear force for chosen strains. The constitutive laws needed for the concrete response are established from shear panel tests. These constitutive relationships can be seen as a way of including the concrete contribution. However, both the truss models and these more enhanced methods use sectional forces determined from an independent overall structural analysis.

If needed, the assessment can be refined with more accurate analysis methods, improved input data and more appropriate safety formats. In Plos et al. ${ }^{26}$ the use of probabilistic analysis, FE analysis, alternative design methods and combinations of these were presented for two prestressed box-girder bridges, including the bridge used for the case study presented here.

\section{Safety format}

The design resistance $R_{\mathrm{d}}$ - that is, the load-carrying capacity with sufficient reliability, can be estimated according to various safety formats; see Sustainable Bridges ${ }^{5}$ and Cervenka et al. ${ }^{20}$ The safety format can be fully probabilistic, semi-probabilistic or deterministic. Some of the formats presented in Sustainable Bridges ${ }^{5}$ were used and compared in this study and are therefore briefly presented below.

A commonly used method to estimate the design resistance is to use safety formats presented in codes, such as the partial safety factor method. These formats are generally developed for section analysis with the sectional forces often determined through linear analysis. However, reducing the material strength properties with partial safety factors will, in a non-linear analysis, influence not only the resistance of the structure but also the distribution of sectional forces and internal stresses. The design resistance is determined by an analysis using material properties calculated with partial safety factors, for all input material parameters.

$$
R_{\mathrm{d}}=r\left(f_{\mathrm{d}}, \ldots\right)
$$

This format gives a deterministic value of the loadcarrying capacity. As previously stated, this is a conceptually doubtful method in combination with non-linear analysis. This method is likely to give conservative results, but it may also be an unsafe method, at least in some theoretical cases. Furthermore, it may cause deviations in structural response; for example, the failure mode may change compared with a scenario where more realistic material properties were used.

The most appropriate way to determine the design resistance for an existing bridge would be to perform a fully probabilistic non-linear analysis. This requires several deterministic non-linear analyses for random sets of input variables such as material properties, geometry, support conditions and loading. A less demanding way is to use a semi-probabilistic format. In Sustainable Bridges ${ }^{5}$ and Cervenka et $a .^{20}$ a format based on semi-probabilistic estimation of the variation coefficient of resistance, the ECOV method, is proposed. For this method two non-linear analyses are needed, one with mean and one with characteristic material properties, $f_{\mathrm{m}}$ and $f_{\mathrm{k}}$ respectively. The loadcarrying capacities determined with the analyses are used to evaluate a global safety factor, $\gamma_{0}$, according to Equations 2 and 3

$$
\begin{aligned}
\gamma_{0} & =\exp \left(\alpha_{\mathrm{R}} \beta V_{\mathrm{R}}\right) \approx \exp \left(0.8 \times 4.7 V_{\mathrm{R}}\right) \\
& \approx \exp \left(3.76 V_{\mathrm{R}}\right)
\end{aligned}
$$

Here, $\alpha$ is the sensitivity factor for resistance reliability and $\beta$ is the reliability index. Typical values are $\alpha=0.8$ and $\beta=4.7$ according to Cervenka et al. ${ }^{20}$

$$
V_{\mathrm{R}}=\frac{1}{1.65} \ln \left(\frac{R_{\mathrm{m}}}{R_{\mathrm{k}}}\right)
$$

where

$$
\begin{aligned}
R_{\mathrm{m}} & =r\left(f_{\mathrm{m}}, \ldots\right) \\
R_{\mathrm{k}} & =r\left(f_{\mathrm{k}}, \ldots\right)
\end{aligned}
$$

The design resistance, $R_{\mathrm{d}}$, is then estimated by dividing the resistance evaluated with mean material properties, $R_{\mathrm{m}}$, by the global safety factor

$$
R_{\mathrm{d}}=\frac{R_{\mathrm{m}}}{\gamma_{0}}
$$

Another semi-probabilistic format is presented in EN 1992-2. ${ }^{19}$ Here, fictive material properties (see Equations 7 to 10) are used in one analysis to determine the load-carrying capacity, which then is divided by a global safety factor, $\gamma_{0}=1 \cdot 27$, to estimate the design resistance

$$
R_{\mathrm{d}}=r\left(\tilde{f}_{\mathrm{ym}}, \tilde{f}_{\mathrm{cm}}, \ldots\right) / \gamma_{0}
$$

where

$$
\begin{aligned}
& \tilde{f}_{\mathrm{ym}}=1 \cdot 1 f_{\mathrm{yk}} \text { for reinforcing steel yield strength } \\
& \begin{aligned}
\tilde{f}_{\mathrm{pm}}=1 \cdot 1 f_{\mathrm{pk}} \\
\text { for prestressing steel yield strength }
\end{aligned} \\
& \begin{aligned}
\tilde{f}_{\mathrm{cm}}=1 \cdot 1 \frac{\gamma_{\mathrm{s}}}{\gamma_{\mathrm{c}}} f_{\mathrm{ck}}=0.843 f_{\mathrm{ck}} \\
\text { for concrete compressive strength. }
\end{aligned}
\end{aligned}
$$

This method is limited to cases where the tensile strength of concrete is not a major parameter influencing the limit state; see Sustainable Bridges. ${ }^{5}$

A structure such as a bridge is subjected to several actions, permanent and variable loads, and creep and temperature deviations. In a non-linear analysis the loads are applied sequentially, in a way similar to a load test. For example, permanent loads and other variable loads than the point loads of traffic are applied before the point loads are increased successively up to failure. Consequently, the axle or bogie load resistance is determined for the bridge subjected to the other loads

Magazine of Concrete Research, 2009, 61, No. 8 
acting on it; that is, the effects of these loads are included in the resistance calculated. Also the actions on a bridge have variations, but this has not been taken into account in the analyses performed in this study.

\section{The modelling method for simulating shear response and shear failure}

To include effects of force redistributions, the construction history and the loading sequence, the whole bridge needs to be modelled. Beam elements are often suitable for modelling of a complete concrete bridge structure. Beam elements are, however, not capable of describing shear cracking and shear failure or a reduced torsional stiffness due to cracking. When modelling the shear response with non-linear FEM, it is important to understand, as far as possible, the nonlinear shear response of reinforced concrete. This is in order to choose the proper level of detailing, element types, material models and so on to use in the model. To be able to simulate the shear response and shear failure, continuum elements ${ }^{27}$ or shell elements ${ }^{18}$ are needed. At the same time it is important to simplify the model to avoid analyses that are too time-consuming. Continuum or shell elements for critical parts of the structure can be combined with beam elements for parts that are not critical; see Plos and Gylltoft ${ }^{13}$ and Lundgren et $a .^{28}$ The modelling of the critical part also, however, needs to be simplified; that is, coarse mesh and full interaction between reinforcement and concrete need to be used. These simplifications will govern the choice of material models and material properties needed.

In Broo et al. ${ }^{18}$ a modelling method was worked out to analyse the shear response and shear failure of reinforced and prestressed concrete members. The method was verified for members subjected to shear, torsion, bending and combinations of these load effects. The FE program Diana ${ }^{29}$ was used to analyse several shear panel tests, orthogonally reinforced and loaded in pure shear, and reinforced and prestressed beam tests loaded in bending, shear and torsion. In the specimens analysed, the shear reinforcement amount varied from $0 \cdot 2 \%$ up to $3 \%$ and the thicknesses of the specimens varied from $0.07 \mathrm{~m}$ up to $0 \cdot 189 \mathrm{~m}$.

In the analyses, the concrete was modelled with fournode curved shell elements. Full interaction was assumed between the reinforcement or prestressing strands and the concrete, by using embedded reinforcement layers. The concrete was modelled with a constitutive model based on non-linear fracture mechanics, and a rotating crack model based on total strain was used. ${ }^{29}$ The hardening of concrete in compression was described by the expression of Thorenfeldt, and the reduction of the strength owing to transverse tensile strains was modelled according to Vecchio and Collins, as described in $\mathrm{TNO}^{29}$ For the tension softening, two approaches were compared; see Figure 2.

(a) The curve by Hordijk, as described in $\mathrm{TNO},{ }^{29}$ where only the fracture energy of plain concrete is taken into account.

(b) A curve modified according to the expression from the MCFT by Collins and Mitchell, ${ }^{30}$ which attempts to take into account also the concrete contribution-that is, tension stiffening, aggregate interlock and dowel action.

The constitutive relations of the reinforcement and the prestressing steel were modelled by the von Mises yield criterion with an associated flow rule and isotropic hardening.

It was shown that four-node curved shell elements with embedded reinforcement could describe the nonlinear shear response and predict the shear capacity. Further, this study implied that an analysis of a reinforced or prestressed concrete member subjected to shear, torsion and bending will predict the load-carrying capacity and the crack widths on the safe side, if

(a) the fracture energy alone is used to define the softening branch of the concrete tensile response

(b) the reduction of the compression strength due to transverse tensile strain is included.

Also some problems were highlighted. If the concrete compressive failure was localised into a small region, whose size did not correspond to the size of the specimens used to calibrate the compression relationship used - that is, the non-linear compression-softening curve of Thorenfeldt - the model could not predict the response. Furthermore, reducing the compressive strength due to lateral strains can result in an unreasonable response and a premature failure.

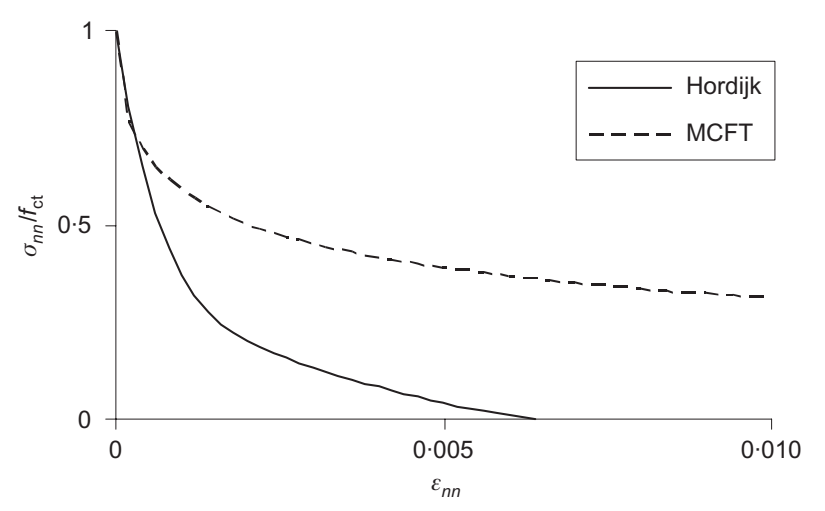

Figure 2. Comparison of tension-softening relationships according to Hordijk as described in TNO, ${ }^{29}$ where only the fracture energy of plain concrete is taken into account; and according to MCFT in Collins and Mitchell ${ }^{30}$ including the concrete contribution when subjected to shear 


\section{A case study}

\section{The Källösund Bridge}

The Källösund Bridge, a prestressed concrete boxgirder bridge, was built in 1958-1959 on the Swedish west coast; see Figure 3. The bridge was constructed with the free cantilevering method and cast-in-situ concrete. The total length of the bridge is about $325 \mathrm{~m}$, divided in four spans with theoretical span widths of $50 \mathrm{~m}, 107 \mathrm{~m}, 107 \mathrm{~m}$ and $50 \mathrm{~m}$. It is supported on three piers and two end abutments. Elevation and plan of the bridge are shown in Figure 4. In 1982 the bridge was complemented with a causeway for pedestrians and bicycles. This causeway is constructed in steel and mounted on the south side of the bridge; see Figure 5, which shows the bridge girder cross-section over the pier and in the mid-span region. The main part of the

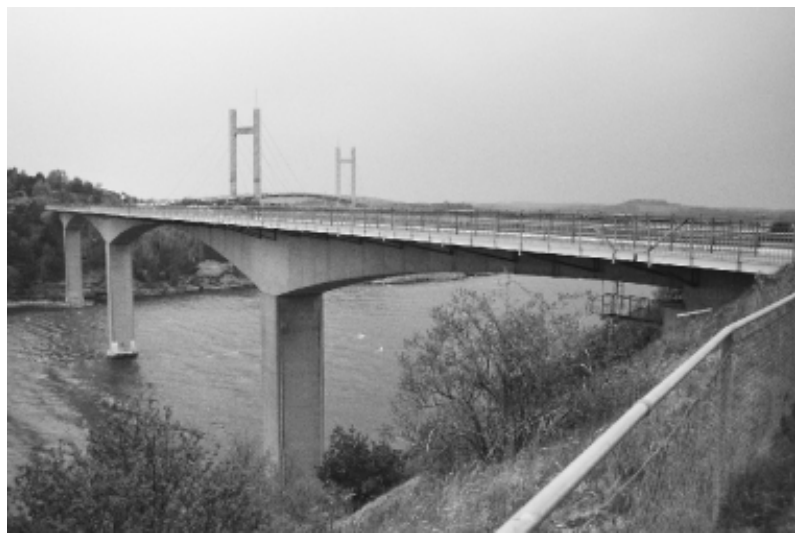

Figure 3. The Källösund Bridge, seen from Stenungsön (in west direction)

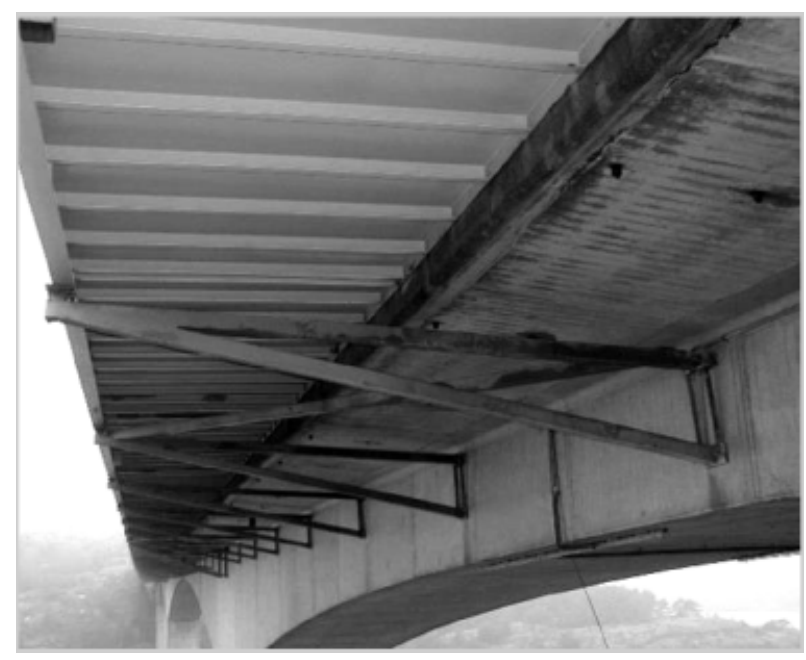

(a)

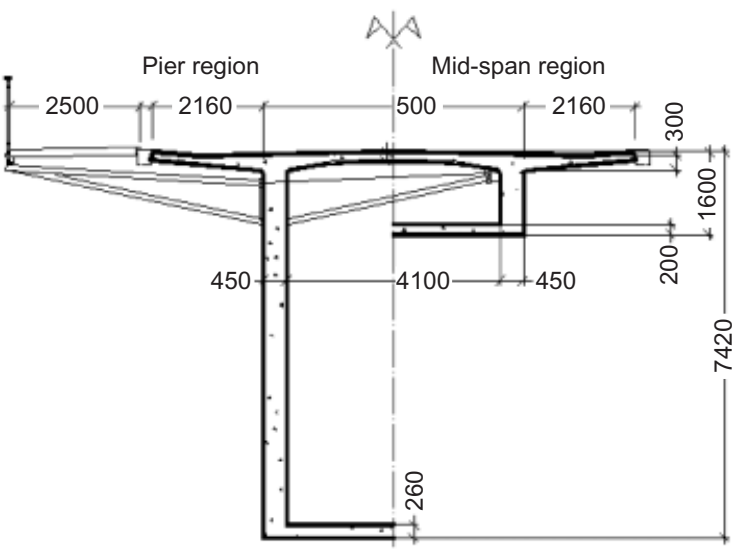

(b)

Figure 5. (a) The bicycle and pedestrian causeway on the south side of the bridge; (b) bridge girder cross-section, including the causeway, in the pier and mid-span region (units: $\mathrm{mm}$ )

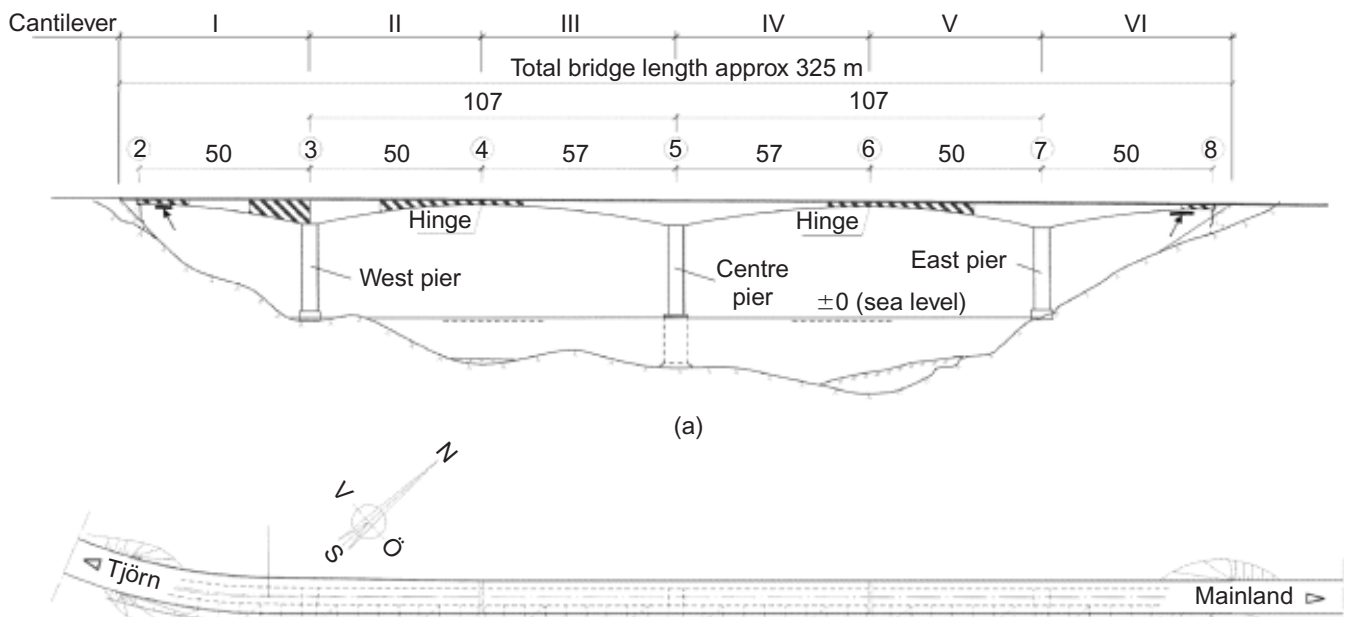

(b)

Figure 4. Elevation and plan of the Källösund Bridge. (Regions with insufficient capacity and critical cross-sections according to the initial assessment are indicated.) Modified from Enochsson et al.: ${ }^{31}$ (a) elevation; (b) plan 
longitudinal reinforcement in the bridge girders is prestressed, and is mostly positioned in the top flange. A part of the longitudinal prestressed reinforcement is bent down diagonally in the webs in the outer parts of the cantilevers; see Figure 6. The bridge slab is also prestressed in the transversal direction with a reinforcement spacing of $500 \mathrm{~mm}$. The prestressing reinforcement consists of bars with a diameter of $26 \mathrm{~mm}$ in grouted ducts. The level of the prestressing is, after long-term losses, about $530 \mathrm{MPa}$ and $620 \mathrm{MPa}$ for the longitudinal and the transversal prestressed reinforcement respectively. The bridge girders have a quite low amount of non-prestressed reinforcement, generally $\phi 10$ s 300; see Figure 7. More detailed descriptions of the bridge can be found in Plos and Gylltoft, ${ }^{13}$ Plos et al., ${ }^{26}$ Enochsson et al., ${ }^{31}$ and Plos. ${ }^{32}$

\section{Previous assessments}

In this study the Källösund Bridge was analysed as a case study, using the modelling method previously worked out. It would have been preferable to make the case study on a prestressed concrete bridge that has been tested to failure owing to shear and torsion. However, full-scale tests on concrete bridges are rare and the authors have not been able to find any suitable tested bridge on which to use the modelling method. The Källösund Bridge has previously been extensively assessed and was judged to have insufficient load-carrying capacity for combinations of shear and torsion.

In connection with a maintenance and repair intervention, both a conventional structural assessment and several enhanced assessments with more advanced methods were performed. In the conventional assessment, linear structural analyses were made and all possible load combinations, type vehicles and traffic load positions were evaluated. For each cross-section the maximum cross-sectional forces were presented. The required reinforcement amount for each crosssection was calculated according to the design methods for concrete structures in the Swedish code BBK 94. ${ }^{33}$ According to this assessment, strengthening was required for combinations of shear and torsion along substantial parts of the bridge; see Figure 8 . The most critical sections were found to be in cantilever II, $26.5 \mathrm{~m}$ and $29.5 \mathrm{~m}$ from the centre of the west pier. Figure 8 shows the critical load combination and the location of the critical section. Figure 7 shows the critical cross-section with reinforcement. For the critical load combination and the critical section, a more enhanced assessment was performed in a project aiming at showing how more advanced methods can be used for more accurate assessments of concrete bridges. ${ }^{26}$ In order to try to reveal a higher load-carrying capacity than the one evaluated in the convectional assessment,

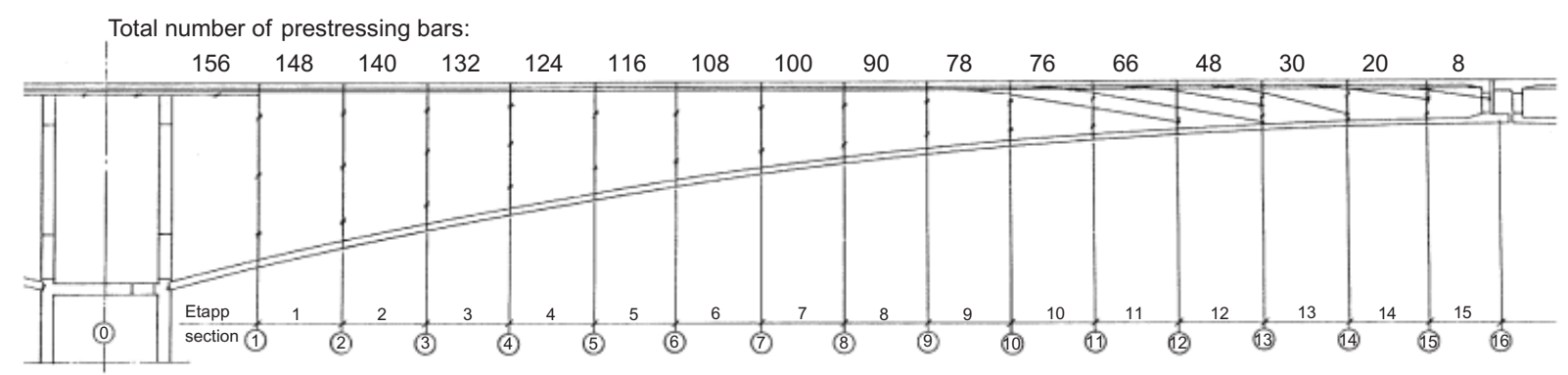

Figure 6. Main prestressing reinforcement in the cantilever II.

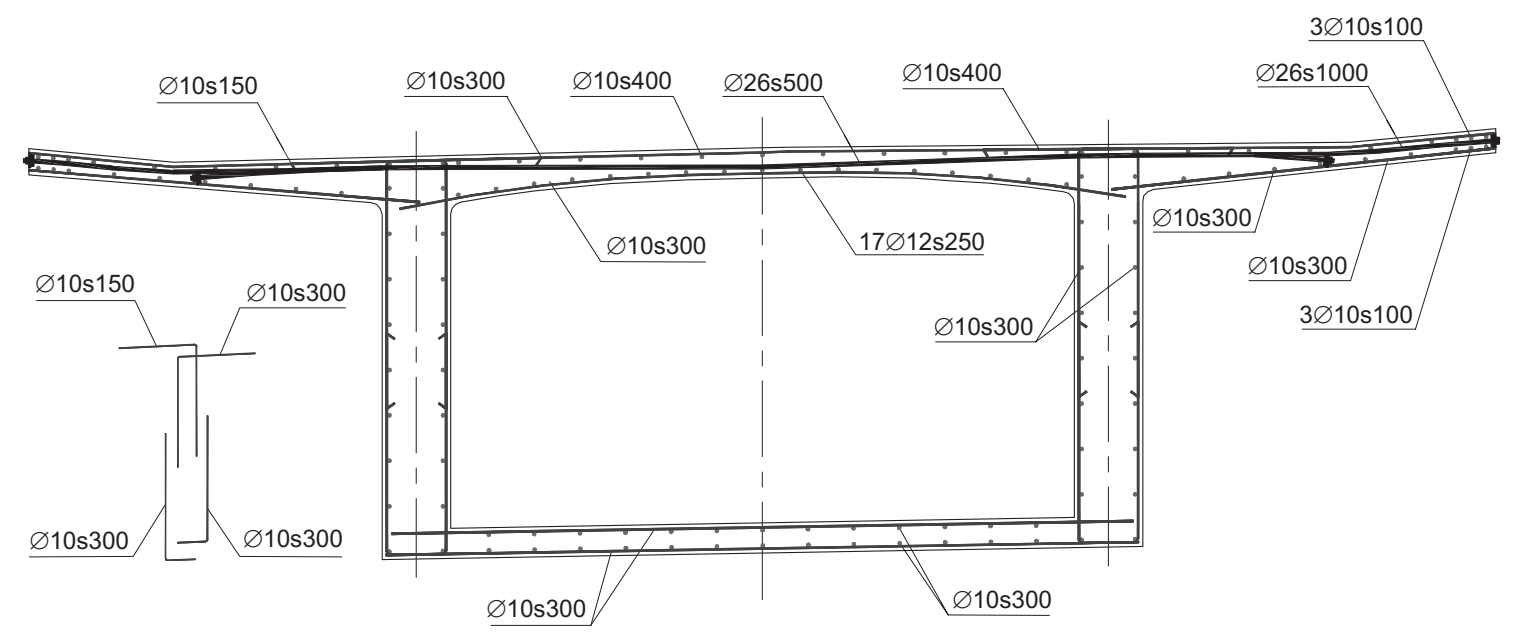

Figure 7. Cross-section and reinforcement layout in the critical section (29.5 m from the west pier, in cantilever II). Longitudinal prestressing tendons not included. Modified from Plos et al. ${ }^{26}$ 


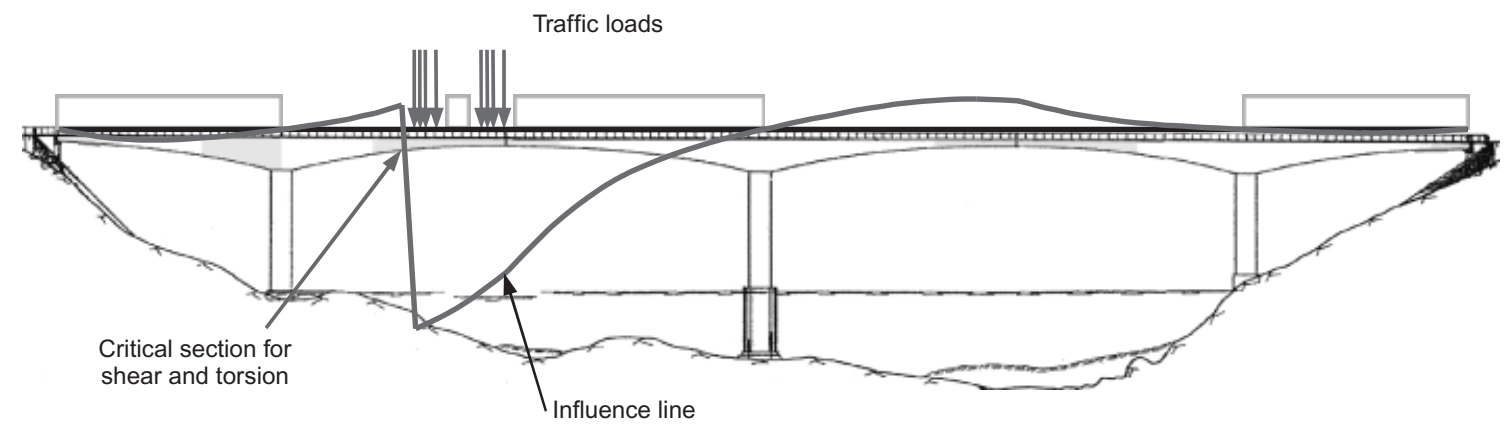

Figure 8. Influence line for the shear force in the critical cross-section and corresponding critical traffic load position. Modified from Plos and Gylltoft ${ }^{13}$

different more enhanced methods were used on the bridge. Probabilistic methods taking material properties and load situation into account were used ${ }^{34}$ as well as improved methods for combinations of shear, torsion and bending. ${ }^{31}$ In particular the MCFT was used to evaluate the load-carrying capacity. According to these evaluations, the bridge was found to have lower bogie load capacity than required. Furthermore, the loadcarrying capacity of the bridge was evaluated by using non-linear FE analyses. ${ }^{13,32}$ Here, a substantially higher capacity was found. However, the modelling method used in the FE analyses was not verified against tests and the results were questioned. ${ }^{26}$ Therefore, the bridge was strengthened with glued fibre-reinforced laminates.

The evaluation performed in this study is improved, compared to the previously undertaken assessment with non-linear FEM, in several respects

(a) the modelling method used is verified

(b) long-term effects owing to concrete creep are taken into account

(c) the reinforcement is modelled more accurately

(d) the final loading with traffic point loads is made with displacement control

(e) several analyses are undertaken to study some safety formats that are suitable for evaluation of the design load capacity by using non-linear analysis.

\section{FE model of the bridge}

The non-linear FE program Diana ${ }^{29}$ and the modelling approach presented above were used to simulate the shear and torsion response of the Källösund Bridge. The model was built up with the same information and with the same simplifications as the model used by Plos, ${ }^{32}$ if nothing else is stated. The whole bridge was modelled, but only the part that was most critical to shear and torsion failure was modelled in detail; see Figure 9. Cantilever II (see Figure 4) was modelled with shell elements and embedded reinforcement according to the modelling method presented. For the shell elements in the top and bottom flange, seven integration points over the thickness were used in order to describe bending properly. For the shell elements in the webs, only three integration points were used in

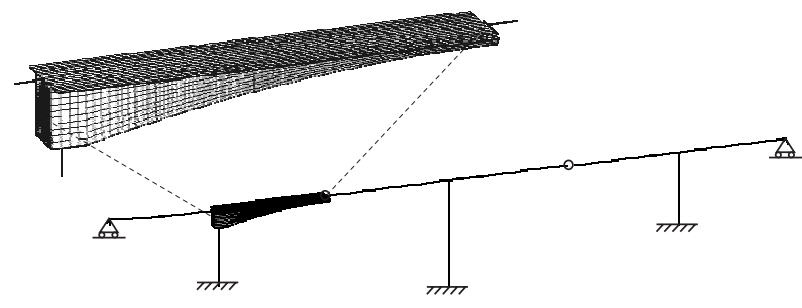

Figure 9. FE model of the Källösund Bridge used for the case study. Only the part of the bridge critical for shear and torsion is modelled in detail with curved shell elements, embedded reinforcement and non-linear material properties. The rest of the bridge is modelled with beam elements and linear material properties

order to save computational time. The rest of the bridge was modelled with two-node beam elements and linear material properties. The bridge was cast in segments that were about $3 \mathrm{~m}$ long. In the model there is one beam element for each segment. The geometric properties of the beam elements, moment of inertia and eccentricity were given the mean values for each segment. The reinforcement and the prestress were not included in the parts modelled with beam elements.

The piers were assumed to be fixed at the bottom end. The end spans were simply supported at the abutments. From the node at each end, two inclined stiff links were used to model the boundary conditions at the correct positions of the abutments. Here, the ends of the stiff links were supported in the vertical and transversal direction; see Figure 10(b). At the mid-span hinges, the vertical and transversal displacements as well as the torsional rotations were kept equal for the nodes on each side. However, the longitudinal displacements and the bending rotations of the connected cantilever ends were uncoupled. The west end of the detailed part was connected to the linear parts - that is, the west end span and the west pier-through stiff links; see Figure 10(a). Three-node beam elements with high stiffness and no density were used to constrain displacements and rotations between the detailed part and the linear part. All nodes at the end section of the detailed part were forced to remain in the plane given by the end rotation of the connected beam element.

Magazine of Concrete Research, 2009, 61, No. 8 


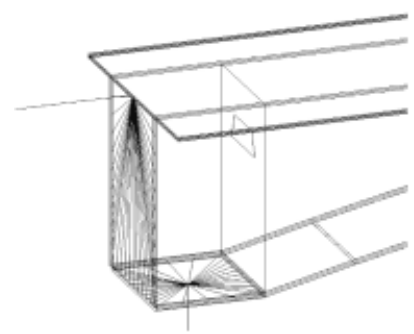

(a)

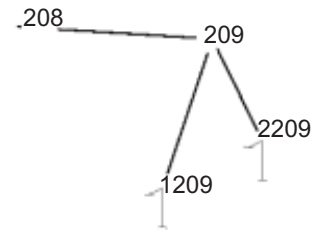

(b)
Figure 10. Stiff links-that is, beams with high stiffness and no density-connecting (a) the non-linear modelled part with the linear modelled parts at the west pier connection, (b) the linear modelled cantilever VI with the abutments

Moreover, the nodes on the part of the cross-section forming the closed box were forced to keep their relative distance to each other, in order to simulate the cross-wall in this section. At the section connected to the pier, the same type of constraints was used.

\section{Material properties}

The material properties used in the analyses are listed in Table 1 and graphically presented in Figures 11 and 12. For non-linear FE analysis the nonlinear responses of the materials are needed. Material models are used to describe these responses; however, characteristics such as tensile strength, compressive strength, Young's modulus and fracture energy are needed as input for these material models.

When the bridge was designed, the concrete classes used were K35 for the piers, K55 for the $50 \mathrm{~m}$ cantilevers, and K50 for the central $57 \mathrm{~m}$ cantilevers. In the analyses, the concrete in the piers was assigned the characteristic concrete strength, $f_{\mathrm{ck}}$, used in the conventional assessment. ${ }^{35}$ The concrete in the cantilevers has been tested and evaluated more extensively. ${ }^{26,31,34}$ However, the values available in Jeppson et al. ${ }^{34}$ were considered too incomplete to evaluate the properties statistically. Instead, in the analyses, the concrete in the cantilevers was given the characteristic concrete

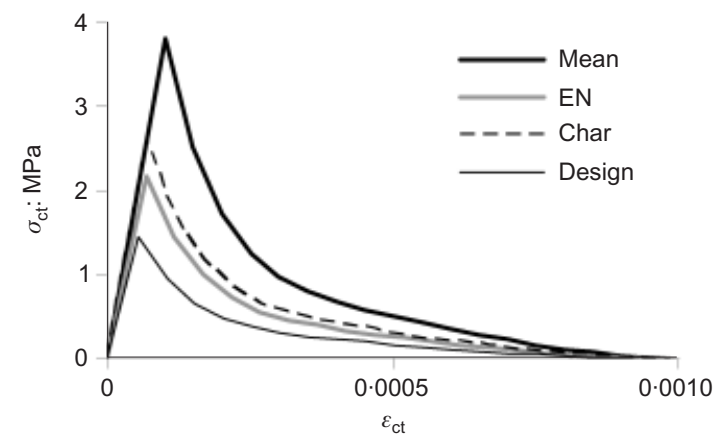

(a)

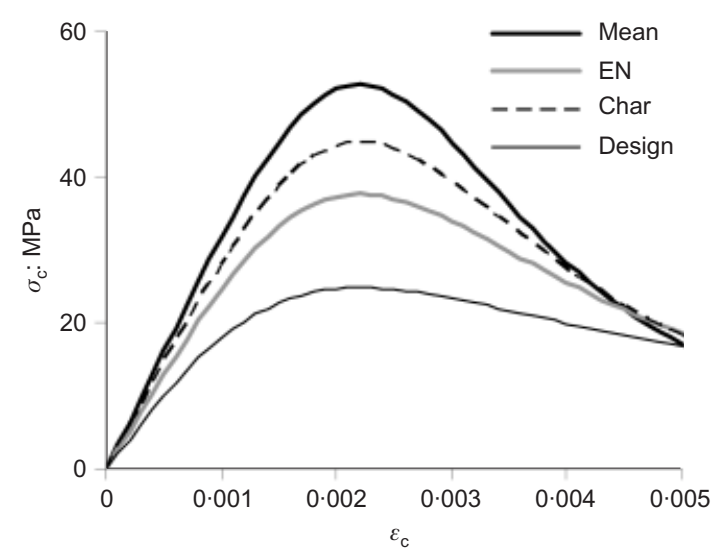

(b)

Figure 11. The concrete uniaxial response for mean, characteristic, EN, and design material properties used in the analyses: (a) the tension-softening curves according to Hordijk as described in TNO; ${ }^{29}$ (b) the compressive softening curve according to Thorenfeldt as described in $\mathrm{TNO}^{29}$

strength, $f_{\text {ck }}$, statistically evaluated from field tests and reported in Plos et al. ${ }^{26}$ All other mean and characteristic concrete material properties were determined from $f_{\text {ck }}$ according to the CEB-FIP model code. ${ }^{36}$ The design values used in the analysis are calculated from the characteristic values according to Boverket, ${ }^{37}$ with partial safety factors $\gamma_{\mathrm{n}}=1.2$ and $\eta \gamma_{\mathrm{m}}$ for each material, as presented in Table 1 . The mean fracture energy was evaluated by assuming a maximum aggregate size of

Table 1. Material properties used in the analyses

\begin{tabular}{|c|c|c|c|c|c|c|c|}
\hline Material & & & $f_{\mathrm{m}}$ & $f_{\mathrm{k}}$ & $f_{\mathrm{m}, \mathrm{EN}}$ & $\eta \gamma_{\mathrm{m}}$ & $f_{\mathrm{d}}$ \\
\hline \multirow[t]{5}{*}{ Concrete } & Piers & $E_{\mathrm{c}}: \mathrm{GPa}$ & $32 \cdot 6$ & $32 \cdot 6$ & $27 \cdot 5$ & $1 \cdot 2$ & $22 \cdot 6$ \\
\hline & Cant & $f_{\mathrm{cc}}: \mathrm{MPa}$ & $52 \cdot 7$ & $44 \cdot 7$ & $37 \cdot 7$ & $1 \cdot 5$ & $24 \cdot 8$ \\
\hline & & $f_{\text {ct }}: \mathrm{MPa}$ & $3 \cdot 80$ & $2 \cdot 58$ & $2 \cdot 17$ & $1 \cdot 5$ & $1 \cdot 43$ \\
\hline & & $E_{\mathrm{c}}: \mathrm{GPa}$ & $37 \cdot 4$ & $37 \cdot 4$ & $31 \cdot 5$ & $1 \cdot 2$ & $26 \cdot 0$ \\
\hline & & $G_{\mathrm{f}}: \mathrm{Nm} / \mathrm{m}^{2}$ & 186 & 126 & 106 & - & 70 \\
\hline \multirow[t]{4}{*}{ Reinforcing steel } & $\phi 10$ & $f_{\mathrm{y}}: \mathrm{MPa}$ & 450 & 392 & 431 & $1 \cdot 15$ & 284 \\
\hline & & $f_{\mathrm{u}}: \mathrm{MPa}$ & 630 & 549 & 603 & $1 \cdot 15$ & 398 \\
\hline & & & $0 \cdot 15$ & $0 \cdot 15$ & $0 \cdot 15$ & - & $0 \cdot 15$ \\
\hline & & $E_{\mathrm{s}}: \mathrm{GPa}$ & 204 & 200 & 220 & $1 \cdot 05$ & 159 \\
\hline \multirow[t]{4}{*}{ Prestressing steel } & $\phi 26$ & $f_{\mathrm{p}}: \mathrm{MPa}$ & 860 & 770 & 847 & $1 \cdot 15$ & 558 \\
\hline & & $f_{\mathrm{u}}: \mathrm{MPa}$ & 1110 & 1000 & 1100 & $1 \cdot 15$ & 725 \\
\hline & & $\varepsilon_{\mathrm{g}}$ & $0 \cdot 07$ & 0.07 & 0.07 & - & 0.07 \\
\hline & & $E_{\mathrm{p}}: \mathrm{GPa}$ & 178 & 174 & 191 & $1 \cdot 05$ & 138 \\
\hline
\end{tabular}




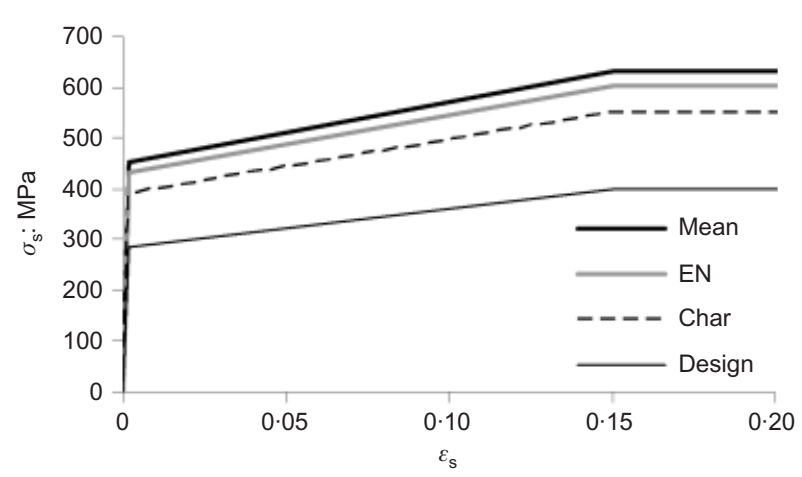

(a)

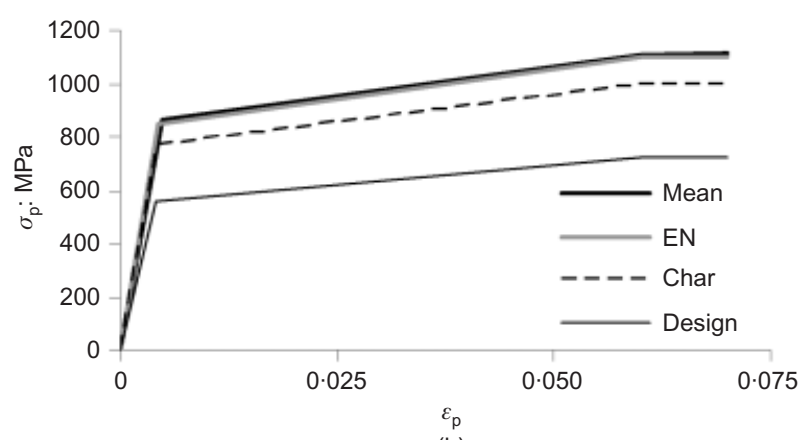

(b)

Figure 12. The steel response for mean, characteristic, EN, and design material properties used in the analyses:

(a) ordinary reinforcement and (b) prestressed reinforcement

$32 \mathrm{~mm}$. The corresponding values were calculated by choosing a crack band width $h=0.3 \mathrm{~m}$ and the same ultimate crack strain $\varepsilon^{\mathrm{cr}}{ }_{\text {enn,ult }}$, for the Hordijk tensionsoftening curve; see Figure 11(a). The crack band width corresponds approximately to the mean crack spacing calculated according to EN 1992-1-1. ${ }^{38}$

The material properties used for the non-prestressed and the prestressed reinforcement are in accordance with the ones reported as statistically evaluated in Plos et $a l .{ }^{26}$ No hardening parameters were presented for the non-prestressed reinforcement. Instead, the values presented in Table 1 are mean values taken from several other test reports using the same kind of reinforcement, from the same time period.

\section{FE analyses of the bridge}

The model was used to make four non-linear FE analyses, in order to evaluate the safety formats presented, one for each set-up of material properties; see
Table 1. The analysis procedure was the same in all analyses if nothing else is stated. The loads were the same as in the analysis by Plos. ${ }^{32}$ However, here the traffic point loads in the last step were applied with deformation control instead of load control as in Plos. $^{32}$

The bridge response was evaluated for design loads in the ULS according to the Swedish assessment regulations for road bridges. ${ }^{22}$ The ULS load case includes permanent loads, traffic loads and wind loads. Longterm effects on the prestressing were taken into account. The overall redistribution of stresses in the bridge due to concrete creep was accounted for in an approximate way, by applying prescribed displacements to the end supports. These displacements were calibrated against measured support reactions in FB_Engineering; ${ }^{35}$ see Table 2. Temperature effects were not taken into account in the analyses.

The analyses were made in steps to include the construction sequence and the loading history; see Figure 13. In the analyses, the loads were gradually increased and the abutments and the mid-span hinges were introduced at certain stages during the construction. The gravity load of the parts included in the model was accounted for by the density of reinforced concrete, $\rho=25 \mathrm{kN} / \mathrm{m}^{3}$. The gravity load of parts not included in the model was applied as external loads. The bridge was loaded with several variable loads simultaneously: crowd load on the causeway, distributed traffic load, horizontal and vertical traffic point loads, and wind loads. The vertical point loads of traffic in the critical load combination consist of four type vehicles, with eight point loads of $0 \cdot 22 B$ for each vehicle; see Vägverket. ${ }^{22}$ Hence, the vertical point loads of traffic were applied to 32 nodes; see Figure 14. To enable deformation-controlled loading for several point loads, a separate statically determined arrangement of stiff beams was modelled. The nodes, where the vertical traffic point loads were applied on the bridge, were tied to have the same vertical displacements as the corresponding bottom end nodes of the loading arrangement. The vertical point loads of traffic were applied by increasing the vertical displacement of one node at the top beam element in the loading structure. The resulting vertical reaction force in this node was used to calculate the applied bogie load $B$ according to

Table 2. Measured support reactions at the abutments and calculated pre-described deformations to the model

\begin{tabular}{l|c|c|c|c}
\hline \multirow{2}{*}{} & \multicolumn{2}{|c|}{ West abutment } & \multicolumn{2}{c}{ East abutment } \\
\cline { 2 - 5 } & North & South & North & South \\
\hline $\begin{array}{l}\text { Support reaction: } \mathrm{kN} \\
\text { Deformation: } \mathrm{mm}\end{array}$ & -401 & -367 & -375 & -535 \\
& $7 \cdot 4$ & $6 \cdot 5$ & $34 \cdot 5$ & $34 \cdot 2$ \\
\hline
\end{tabular}




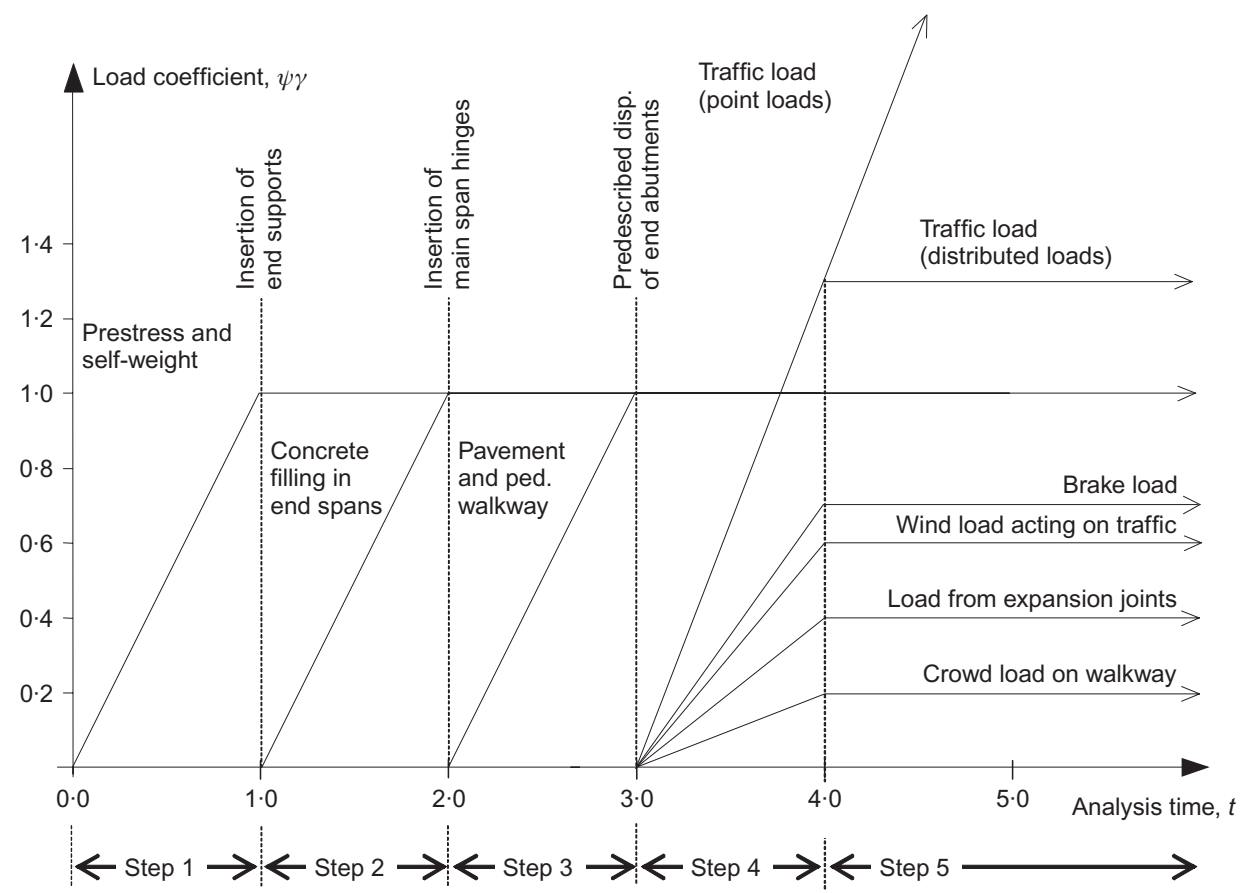

Figure 13. Loading sequence and construction history of the bridge for analysis in the ULS, modified from Plos and Gylltoft ${ }^{3}$
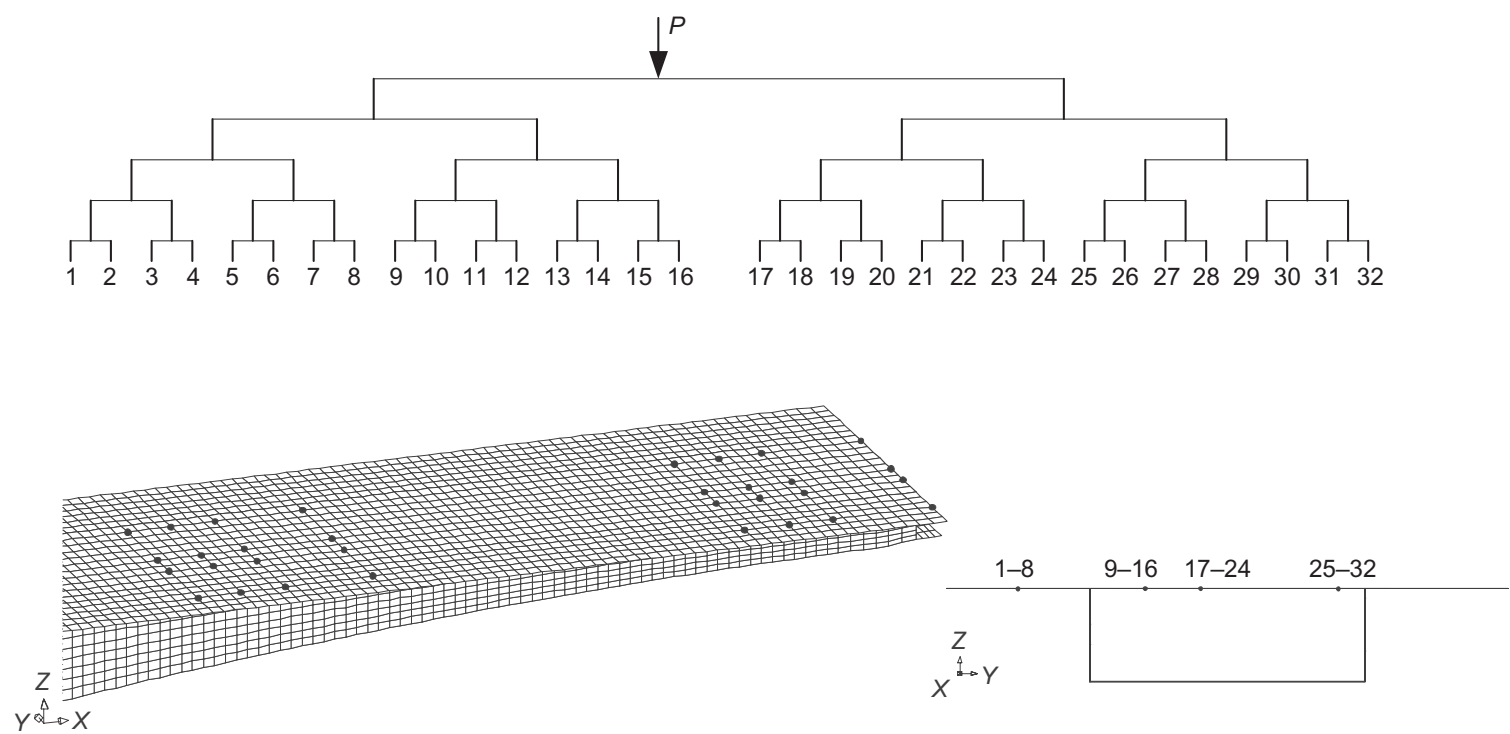

Figure 14. The point loads of the vertical traffic load were applied in 32 points (on 32 nodes) on the top flange, using a statically determined arrangement of stiff beams

$$
B=190+\frac{P}{32 \times 0 \cdot 22 \xi} \mathrm{kN}
$$

where a dynamic multiplication factor $\xi=1.06$ evaluated in $\mathrm{Plos}^{32}$ was used.

In the first step of the analyses (see Figure 13), the prestressing forces were released and the gravity load of the structure was applied. At this stage, only the piers were supported. In the next step, the end abutments were introduced - that is, the nodes were supported in the vertical direction-before a gravity load from concrete filling in the end spans was applied. In the third step, the hinges in the mid-spans were intro- duced. The remaining parts of the permanent loads were then applied, for example the gravity load from the pavement and the causeway, which completed the construction phase. In the next step, the pre-described deformations of the end abutments were introduced, to account for the effects of concrete creep; see Table 2 . Thereafter, the variable loads were applied up to their design values, which included the point loads of the vertical traffic load up to the bogie load $B=190 \mathrm{kN}$. The final failure was reached, in the last step, by increasing the vertical point loads of the traffic to obtain the bogie load resistance, $B_{\mathrm{R}}$. 
In the FE analyses, an implicit solving method was used. In the final step, the loading was made with constant deformation increments of $1.0 \mathrm{~mm}$. For each increment, equilibrium was found by using the BFGS secant iteration method. ${ }^{29}$ A line search algorithm guided with default values. ${ }^{29}$ was used to increase the convergence rate in the iteration process. The analysis was continued if the specified displacement convergence criterion was fulfilled, according to default value; see $\mathrm{TNO}^{29}$ If the convergence criterion was not fulfilled within 200 iterations, the analysis was stopped.

\section{Results from the analyses}

The results shown are from the analysis with mean material properties if nothing else is stated. The response was linear for the whole bridge when subjected to all permanent loads. This can be seen in Figure 15, showing the vertical support reaction in the west pier against deflection of the cantilever II end. Figure 15 also indicates which part of the loading each part of the response emanates from.

In Figure 16 the increase of the bogie load $B$ against the applied deformation is shown for the analyses with: mean material properties, characteristic material properties, and the material properties accord-

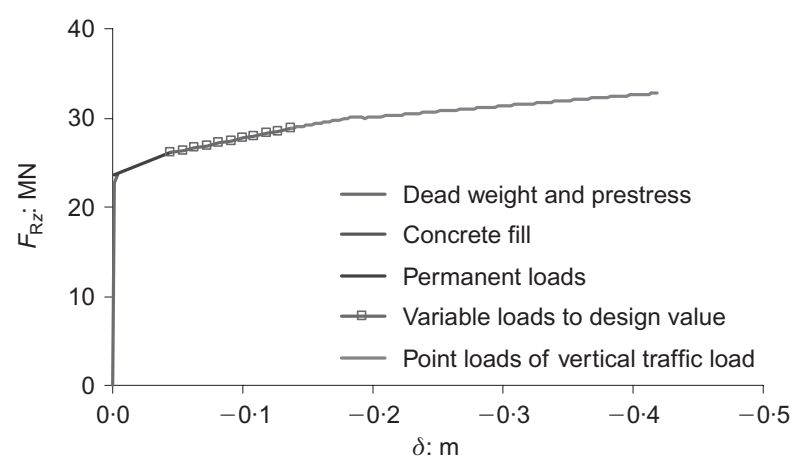

Figure 15. Vertical support reaction in the west pier plotted against vertical displacement of the cantilever II end

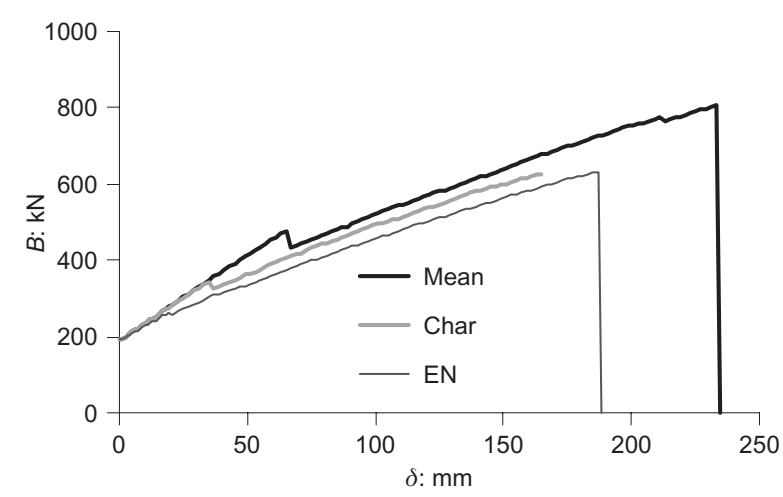

Figure 16. The vertical traffic point load (bogie load) plotted against the applied deflection as result from analyses with mean, characteristic and material parameters according to EN 1992-1 respectively ing to the method in EN 1992-2, respectively. The maximum bogie loads obtained from these analyses were $B_{\mathrm{Rm}}=806 \mathrm{kN}, \quad B_{\mathrm{Rk}}=626 \mathrm{kN} \quad$ and $B_{\mathrm{REN}}=631 \mathrm{kN}$ respectively. As can be seen from the results, the response in the analyses was similar and all three analyses showed the same failure mode. Even if the shear resistance limited the load-carrying capacity in the evaluations previously performed, the failure obtained in these FE analyses was attributable to bending, see Figure 17. However, shear cracks were developed in large regions in the webs, so a shear response was still observed. In the analysis with mean material properties, the cracking of the concrete started at $B=476 \mathrm{kN}$, with flexural-shear cracks, going through the top flange and down into the webs; see Figure 18. The cracks occurred in the sections where the prestressing tendons are anchored in the top flange. When the web cracked, yielding was initiated in the vertical web reinforcement owing to the low reinforcement amount, 0.16\%; see Figure 19. More cracking occurred, both in the top flange and in the webs, when the load was increased. In the part of the cantilever where the bending mode changed from tension in the top to tension in the bottom, the top element row of the south web cracked in shear; see Figure 20. Thereafter, when a bending crack developed in the bottom of the cross-section close to the end of the cantilever, the concrete compressive strength in the top of the web was reduced due to lateral tensile strains. Hence, the concrete in the compressive zone crushed when the tensile reinforcement in this section yielded owing to the low remaining compressive strength; see Figures 21 and 22.

In the analysis with all material properties given their design values, the failure occurred for a bogie load lower than the required design bogie load, $B=$ $190 \mathrm{kN}$ - that is, for a load level lower than when the displacement-controlled loading started. To obtain a clearly interpretable maximum bogie load for this analysis, the point loads of the vertical traffic load were excluded from the fourth load step including variable loads up to the design value. The point loads were then applied by displacement-controlled loading in the last step. The maximum obtained bogie load was then $B_{\mathrm{Rd}}=182 \mathrm{kN}$; see Figure 23. Also this analysis showed the same failure mode as in all the other analyses - that is, crushing of concrete owing to bending. In this analysis the shear cracks in the south web occurred for a bogie load of $B=95 \mathrm{kN}$, when the top flange was still uncracked. For a bogie load of $B=134 \mathrm{kN}$, shear cracks occurred also in the north web and bending cracks occurred in the top flange.

Figure 24(a) shows the magnitude of the torsional moment that was transferred through the link between cantilever II and cantilever III. It can be seen that more of the torsional moment was transferred after shear cracking of cantilever II. This can be compared with how much shear force was transferred (see Figure 
$\operatorname{S}_{>X}$

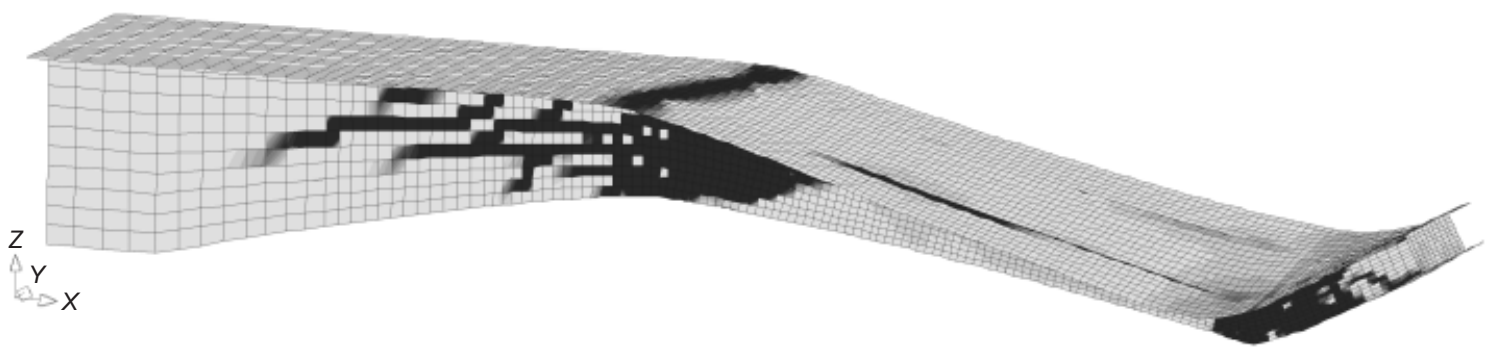

Figure 17. Deformed shape of cantilever II after maximum load. Result from analysis with mean material properties

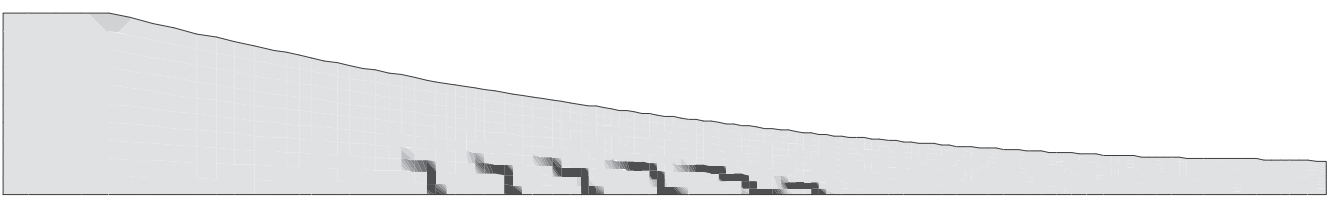

North web

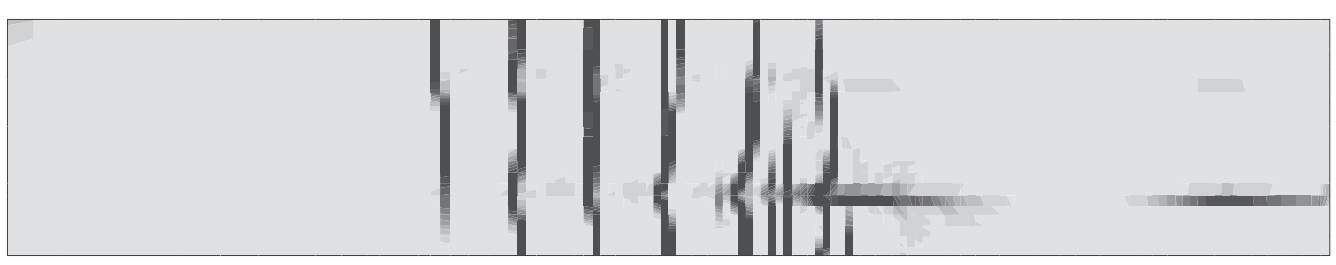

0

$0 \cdot 1 \mathrm{E} \times 10^{-3}$

$0 \cdot 2 \mathrm{E} \times 10^{-3}$

$0.3 \mathrm{E} \times 10^{-3}$

$0.4 \mathrm{E} \times 10^{-3}$
$0.5 \mathrm{E} \times 10^{-3}$

$0.6 \mathrm{E} \times 10^{-3}$

$0.7 \mathrm{E} \times 10^{-3}$

$0.8 \mathrm{E} \times 10^{-3}$

$0.9 \mathrm{E} \times 10^{-3}$

Top flange

I $0.1 \mathrm{E} \times 10^{-2}$

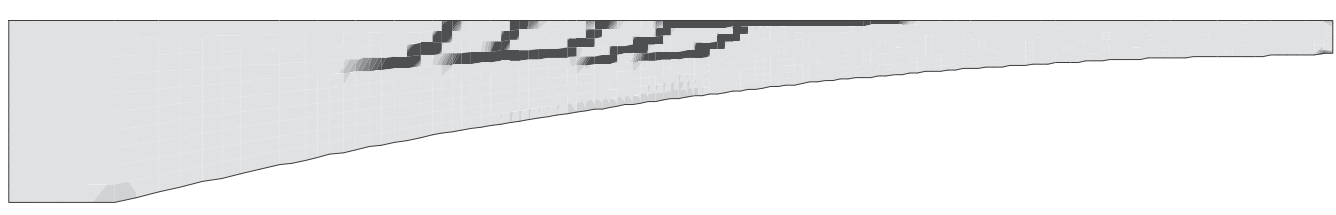

South web

Figure 18. Cantilever II north web, top flange and south web, principal tensile strain when the cracking starts, load $B=476 \mathrm{kN}$. Result from the analysis with mean material properties

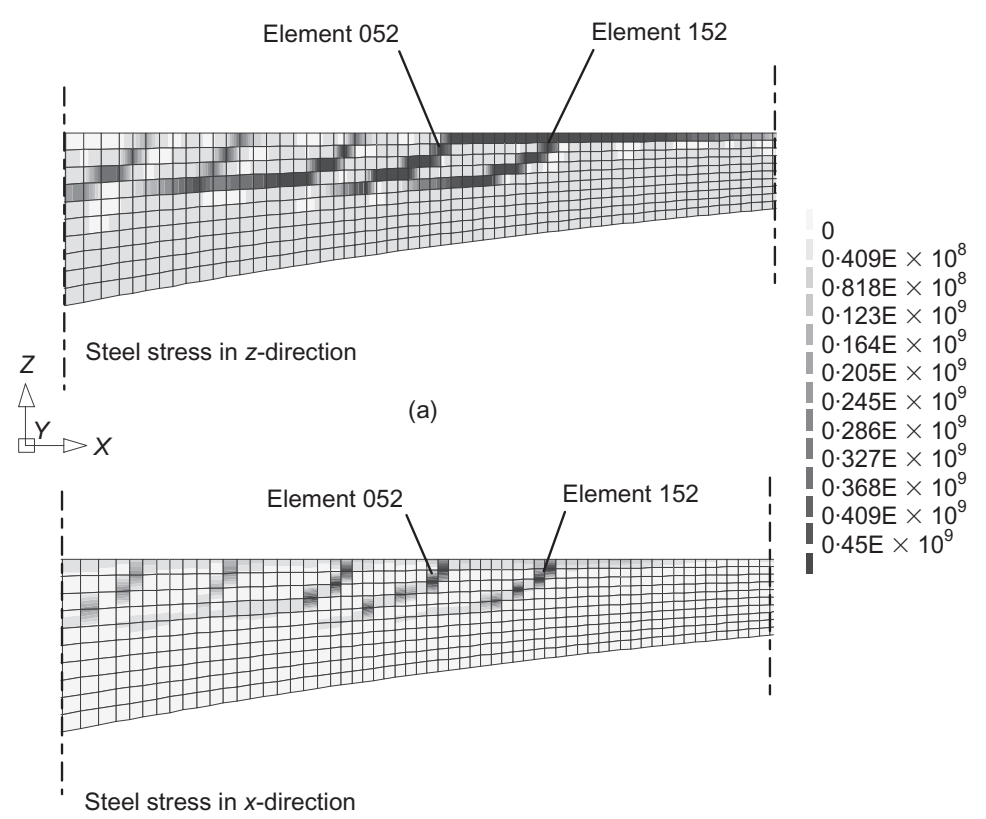

(b)

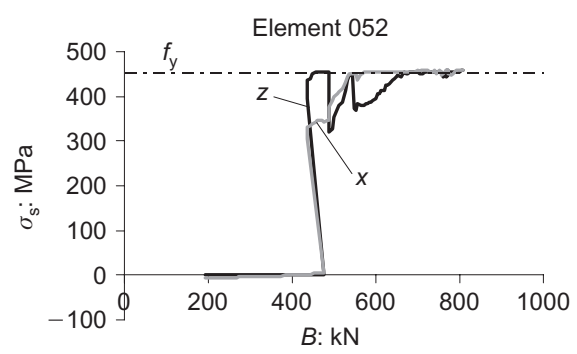

(c)

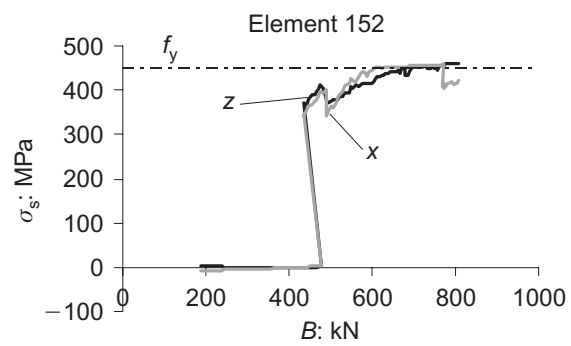

(d)

Figure 19. Results from the analysis with mean material properties. Steel stress in the outer reinforcement in the south web when the concrete cracks: (a) vertical (z-direction), (b) longitudinal (x-direction), (c) and (d) steel stress against bogie load for reinforcement element 052 and 152 , respectively 

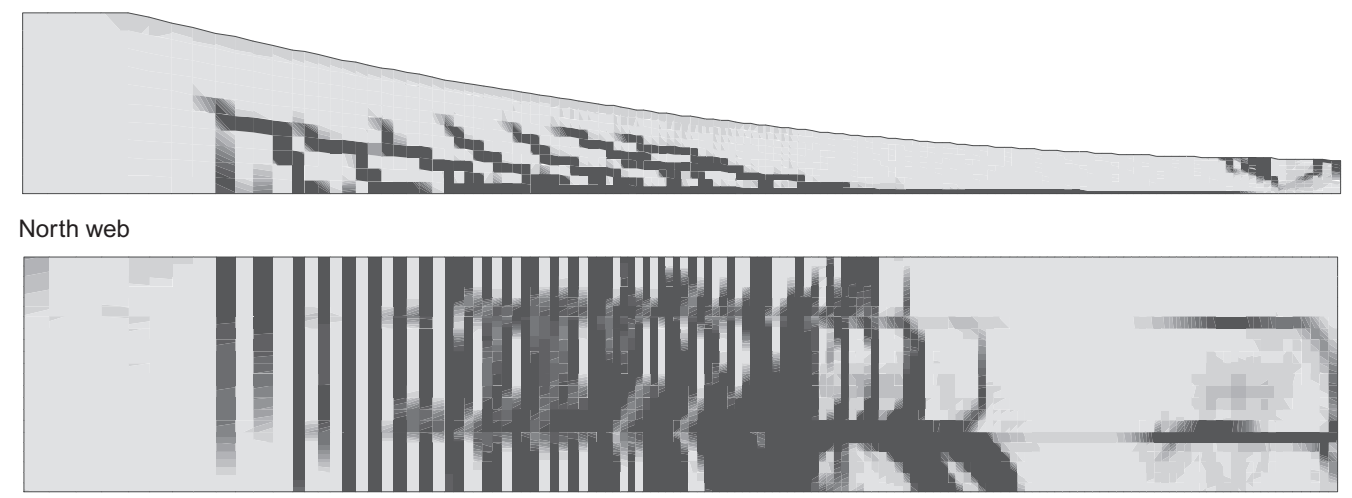

Top flange

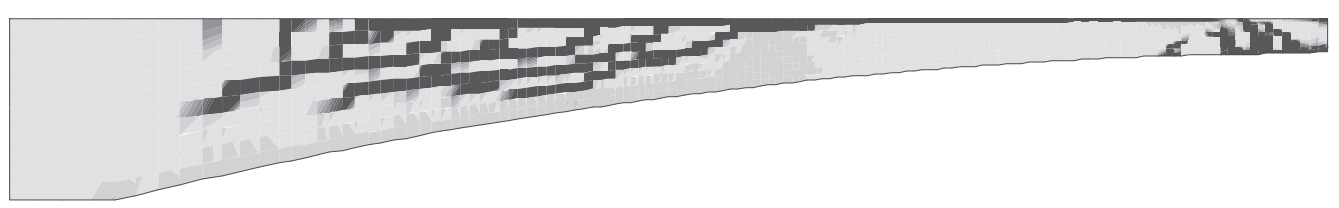

0

$0 \cdot 1 \mathrm{E} \times 10^{-3}$

$0.2 \mathrm{E} \times 10^{-3}$

$0.3 \mathrm{E} \times 10^{-3}$

$0.4 \mathrm{E} \times 10^{-3}$

$0.5 \mathrm{E} \times 10^{-3}$

$0.6 \mathrm{E} \times 10^{-3}$

$0.7 \mathrm{E} \times 10^{-3}$

$0.8 \mathrm{E} \times 10^{-3}$

$0.9 \mathrm{E} \times 10^{-3}$

$0.1 \mathrm{E} \times 10^{-2}$

Figure 20. Cantilever II north web, top flange and south web, principal tensile strain at maximum load from analysis with mean material properties

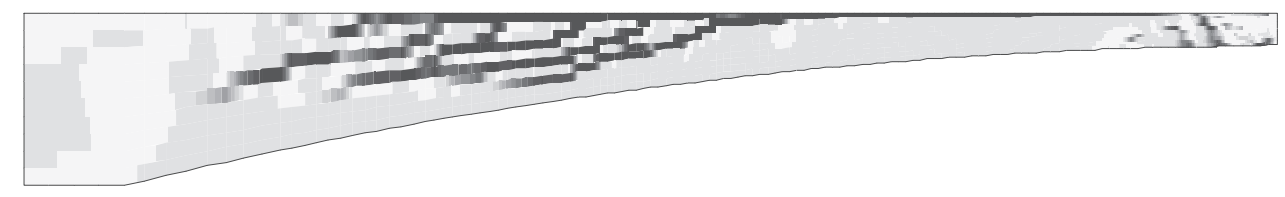

Steel stress in z-direction

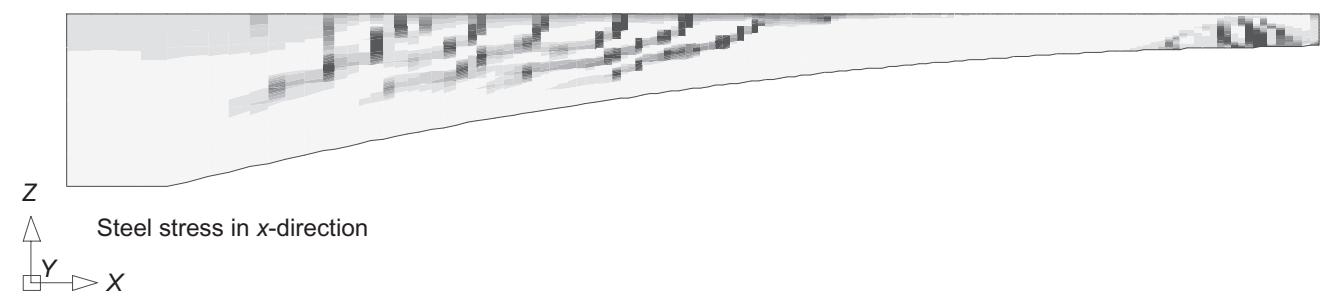

0

$0.45 \mathrm{E} \times 10^{8}$

$0.9 \mathrm{E} \times 10^{8}$

$0.135 \mathrm{E} \times 10^{9}$

$0.18 \mathrm{E} \times 10^{9}$

$0.225 \mathrm{E} \times 10^{9}$

$0.27 \mathrm{E} \times 10^{9}$

$0.315 \mathrm{E} \times 10^{9}$

$0.36 \mathrm{E} \times 10^{9}$

$0.405 \mathrm{E} \times 10^{9}$

$0.45 \mathrm{E} \times 10^{9}$

Figure 21. Steel stress in the outer reinforcement, vertical (z-direction) and longitudinal (x-direction), in the south web. Results from the analysis with mean material properties

24(b)), which shows that the shear cracking had almost no effect on the shear transfer.

As can be seen in Figure 20, a large part of the south web is cracked in shear. When the load increased, the strain localised in a smaller region, which indicates a main shear crack; see Figure 25. This main shear crack developed between section $17.5 \mathrm{~m}$ and section $26.5 \mathrm{~m}$, measured from the centre of the west pier. The inclination of this main shear crack could be estimated as approximately $20^{\circ}$.

Table 3 presents the load-carrying capacity, expressed as bogie load resistance, estimated according to the safety formats presented - that is, the semi-probabilistic ECOV method (ECOV), the method presented in EN 1992-2 (EN) - and by using partial safety factors (PSF). The bogie load resistances determined with the safety formats are also related to the maximum bogie load obtained from the analysis with mean material properties. It should be mentioned that in these calculations and analyses, only variations in material properties and not in actions have been accounted for.

\section{Discussion}

The non-linear FE analysis undertaken with characteristic material properties showed a maximum bogie load of $626 \mathrm{kN}$. This is about $50 \%$ higher than in the previous analysis made by Plos and Gylltoft. ${ }^{13}$ The analyses made in this study were improved, as mentioned, but also performed with other types of elements and other material models. In the analysis undertaken by Plos and Gylltoft ${ }^{13}$ the web started to crack in shear for a bogie load of $B=360 \mathrm{kN}$, and after a small increase of load the solution was not convergent, which resulted in a maximum load of $B=410 \mathrm{kN}$. In the Magazine of Concrete Research, 2009, 61, No. 8 


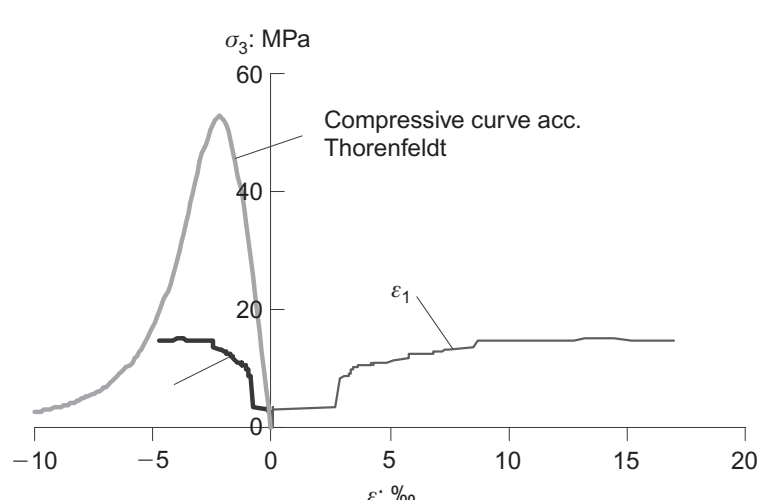

(a)

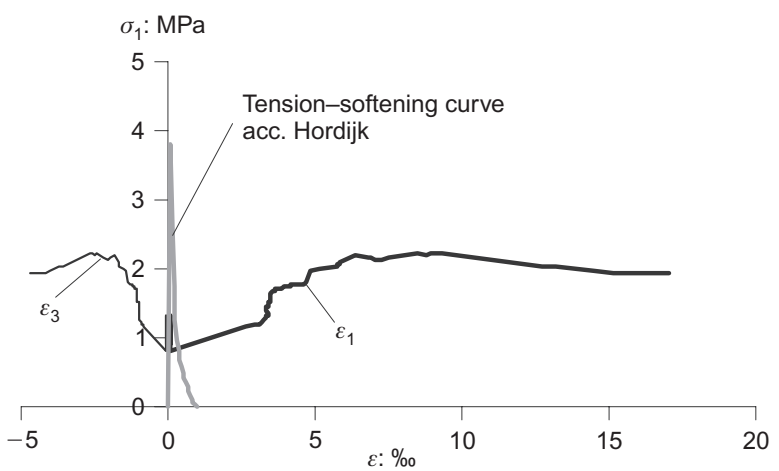

(b)

Figure 22. Results of one concrete element in the top of the south web, from analysis with mean material properties.

(a) Principal compressive stress against principal strains compared with the concrete compressive curve according to Thorenfeldt without reduction owing to lateral tensile strains. (b) Principal tensile stress against principal strains compared with the concrete tension-softening curve according to Hordijk

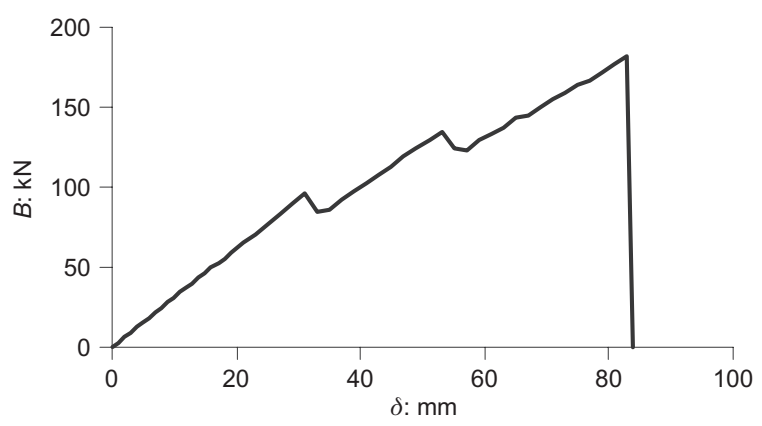

Figure 23. The vertical traffic point load (bogie load) against the applied deformation as result from the analysis with design material properties

present analysis, the shear cracks in the web occurred for a bogie load of $B=344 \mathrm{kN}$ and the maximum load was $B=626 \mathrm{kN}$. The main part of the increased capacity is probably governed by the use of a more stable material model for cracked concrete and by the displacement-controlled loading, which gives a possibility to increase the load after occurrence of shear cracks in the web. Taking into account the hardening of the ordinary reinforcement also increased the load-carrying capa-

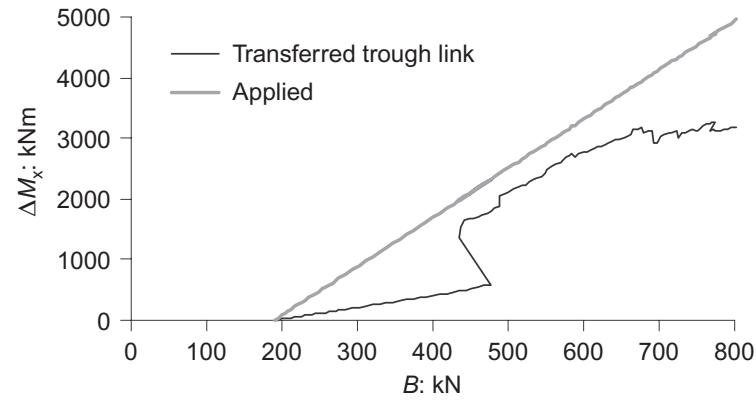

(a)

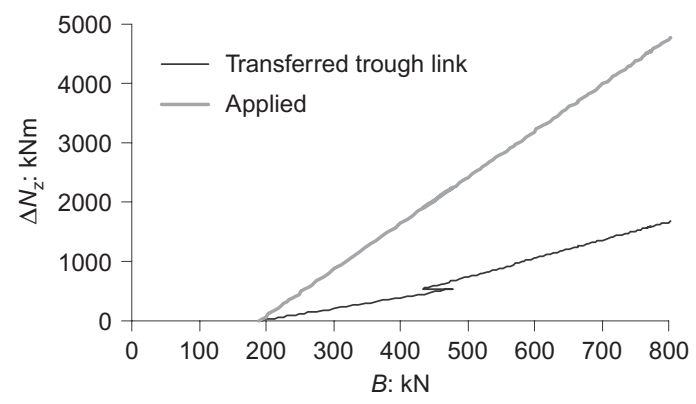

(b)

Figure 24. Results from analysis with mean material properties. Applied bogie load B against increase of (a) torsional moment $M_{x}$ and (b) vertical shear $N_{z}$

city; this increase was, however, quite small owing to the failure mode.

In Figure 22 it can be seen that, even though the principal tensile strain for a cracked element is larger than the ultimate crack strain, tensile stresses are transferred. This may be due to a known drawback with rotating crack models when the orientation of the crack band differs from the orientation of the principal tensile strains. ${ }^{39}$ In the previously analysed shear panel tests, no stresses were transferred after the ultimate crack strain was reached. ${ }^{18}$

The analysis with partial safety factors, using design values of the material properties, gave a very conservative load-carrying capacity, see Table 3 . This was because the effects from both shear and bending interacted in the part of the cantilever where the failure occurred; the reduced concrete compressive strength owing to lateral tensile strains affects the bending moment capacity considerably in this part. The south web cracked for a low bogie load due to the low value of the concrete tensile strength, $f_{\text {ctd }}=1.43 \mathrm{MPa}$. When the bending crack close to the end developed later, the lateral tensile strains in the top of the web had increased greatly, and the already low concrete compressive strength - that is, the design value-decreased even more. Consequently, the moment capacity was influenced both by the concrete tensile strength and by the concrete compressive strength. In a normal bending failure, either the concrete compressive strength or the steel strength will govern the moment capacity. As can be seen in Table 3, the other two safety formats gave approximately the same results, namely a load-carrying 


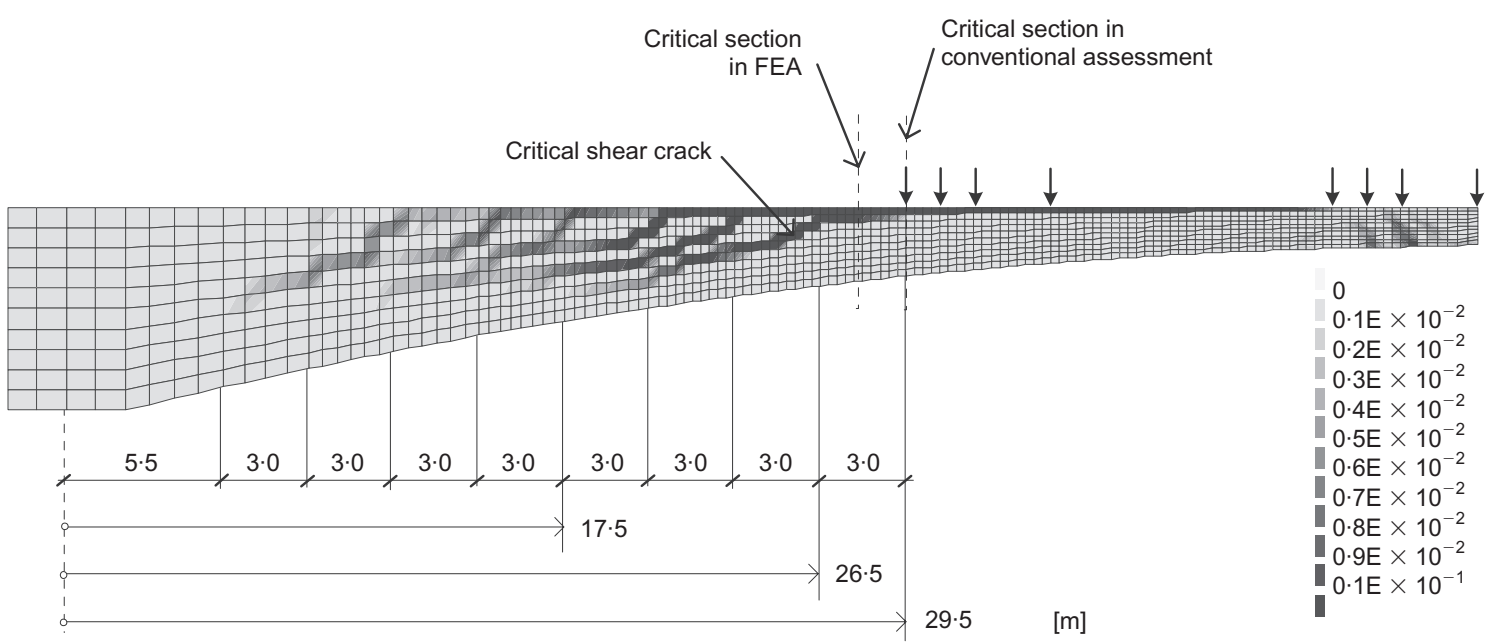

Figure 25. Principal tensile strains in the south web at maximum load as result from the analysis with mean material properties. Assumed critical section was $29.5 \mathrm{~m}$ from centre of the west pier; in the analysis the main shear crack develops between sections $17.5 \mathrm{~m}$ and $26.5 \mathrm{~m}$ from centre of west pier

Table 3. Load-carrying capacity for combined shear and torsion, expressed as a bogie load resistance and safety level

\begin{tabular}{l|c|c|c|c|c}
\hline \multirow{2}{*}{} & \multicolumn{2}{|c|}{ Previously made assessment } & \multicolumn{3}{c}{ Assessment made in this study } \\
\cline { 2 - 6 } & Conventional & FEA & PSF & EN & ECOV \\
\hline$B_{\mathrm{R}}: \mathrm{kN}$ & $<210$ & 250 & 182 & 497 & 454 \\
$B_{\text {mean }} / B_{\mathrm{R}}$ & - & - & 4.42 & 1.62 & 1.78 \\
\hline
\end{tabular}

capacity about $80 \%$ higher than in the previously made FE analysis and more than $100 \%$ higher than in the conventionally made assessment. The disadvantage with the ECOV method mentioned by Cervenka et al. ${ }^{20}$ is the need of making two analyses. However, in the current authors' opinion, the effort of creating a model is sufficiently larger than the effort of running two analyses while only changing the material properties. Moreover, the analysis undertaken with mean material properties simulates the most probable response and would preferably be made anyhow.

From the non-linear FE analyses presented here, it can be seen from Figure 25 that the main shear crack developed between section $17.5 \mathrm{~m}$ and section $26.5 \mathrm{~m}$, which also agrees with the results from the previous analyses made by Plos and Gylltoft. ${ }^{13}$ The previous structural assessment using analytical calculation methods was made with sectional forces for section $29.5 \mathrm{~m}$ and cross-sectional values for this section. ${ }^{31}$ All these analytical calculations indicate that the section needed to be strengthened to resist a bogie load of $B=210 \mathrm{kN}$.

The higher load-carrying capacity achieved, using non-linear FE analysis for the assessment compared to conventional methods, is mainly governed by the location and inclination of the critical shear crack. The web height increases in the shear crack direction. This influences the length of the shear crack and the amount of reinforcement activated in the shear crack. This is not taken into account in the conventional assessment; see Figure 26 and Table 4. Assuming the same critical section as in the conventional assessment, but with the correct length of the shear crack, the reinforcement contribution to the shear capacity for one web increase with $13 \%$ and $39 \%$ for a crack inclination correspondent to $\cot \theta=1$ and $\cot \theta=2 \cdot 5$, respectively. For the

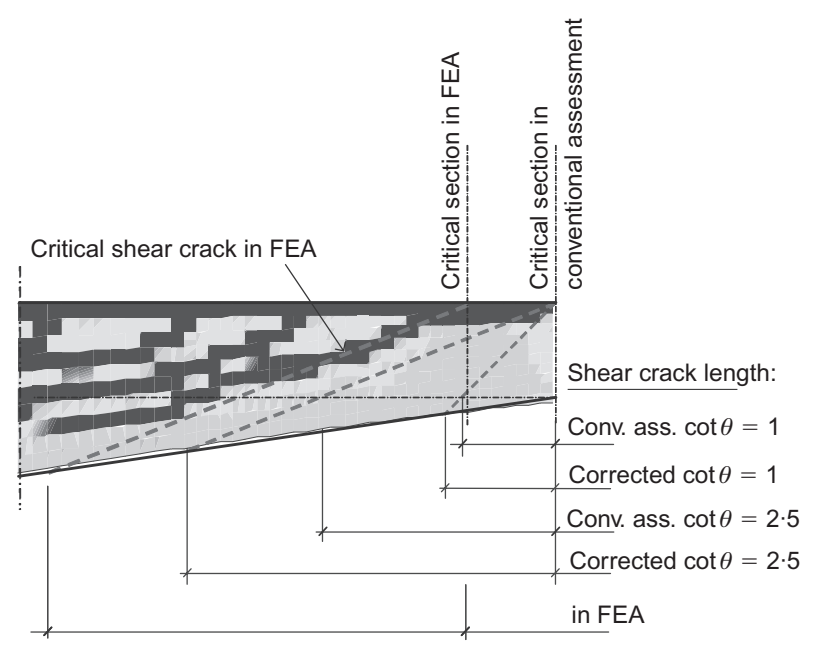

Figure 26. Length of shear crack calculated with the conventional assessment illustrated on the south web, compared with the length of the critical shear crack from the analysis with mean material properties

Magazine of Concrete Research, 2009, 61, No. 8 
Table 4. Contribution from the shear reinforcement to the shear capacity determined from a truss model. Only the shear crack in the south web is considered for the calculations

\begin{tabular}{l|c|c|c}
\hline \multirow{2}{*}{} & \multicolumn{3}{|c}{$V_{\mathrm{s}}: \mathrm{kN}$} \\
\cline { 2 - 4 } & $\begin{array}{c}\text { In the conventional } \\
\text { assessment }\end{array}$ & Corrected & FEA \\
\hline $\cot \theta=1$ & 537 & 605 & - \\
$\cot \theta=2 \cdot 5$ & 1343 & 1866 & 1988 \\
\hline
\end{tabular}

shear crack in the FE analysis this increase was even higher, namely $48 \%$. The redistribution of torsional moment owing to cracking may also have a positive influence on the capacity. However, the redistribution of the torsional moment shown in Figure 24(a) could be questioned, because cantilever III is modelled with linear response. If the load effect in cantilever III is high enough to cause cracking, the stiffness of this part would decrease and the redistribution would have become smaller.

\section{Conclusions}

In this study it was shown, with a case study, that the modelling method using shell elements with non-linear material response for the critical part of a bridge, in combination with beam elements and linear response for the rest of the bridge, can simulate the shear response. Although a final shear failure was not achieved in the analyses, it could be concluded that the shear capacity of this part of the bridge, for this load combination, is higher than the load-carrying capacity determined.

The bridge used for the case study presented has previously been evaluated both with conventional methods and with non-linear FE analysis; see Plos and Gylltoft. ${ }^{13}$ The evaluation in this study was improved in several respects: the FE modelling method used was verified, the final loading was made in a displacementcontrolled process, effects of creep and reinforcement hardening were included, and safety formats suitable for non-linear analysis were adopted. Here, two semiprobabilistic formats, namely the so-called ECOV method and the method presented in EN 1992-2, were used and compared with the deterministic format using partial safety factors.

The FE analysis performed in this study revealed a load-carrying capacity corresponding to about $80 \%$ higher bogie load than in the previously performed FE analysis and over $100 \%$ higher than in a conventionally made assessment. The higher load-carrying capacity shown using non-linear FE analysis for the assessment, compared to conventional methods, is chiefly governed by the location and inclination of the main shear crack. Most of the increased capacity compared with the pre- vious $\mathrm{FE}$ analyses is probably due to the use of a more stable material model for cracked concrete and to the displacement-controlled loading.

According to the investigated safety formats, for this structure and this particular load combination, the analyses with partial safety factors (material properties with design values) give a very conservative loadcarrying capacity, compared with the more correct semi-probabilistic formats for non-linear FE analysis.

In the case study presented, only one critical load combination and one critical region were evaluated. In a complete assessment of a bridge, alternative load cases also need to be evaluated.

\section{Acknowledgements}

The research was financed by the Swedish Road Administration (Vägverket) and the Swedish Rail Administration (Banverket).

\section{References}

1. Mokhtar A.-S. A. and Ghail A. Computer analysis and design of concrete beams and girders. Journal of Structural Engineering, 1988, 114, No. 12, 2669-2691.

2. Shushkewich K. W. Approximate analysis of concrete box girder bridge. Journal of Structural Engineering, 1988, 114, No. 7, 1644-1657.

3. Picard A. and Massicotte B. Serviceability design of prestressed concrete bridges. Journal of Bridge Engineering, 1999, 4, No. 1, 48-55.

4. Shushrewich K. W. Transverse analysis of strutted box girder bridges. Journal of Bridge Engineering, 2006, 11, No. 1, $33-47$.

5. Sustainable Bridges. D4.2 Guideline for load and resistance assessment of existing European railway bridges. D4_2-WP405-070521, 2007 see http://www.sustainablebridges.net.

6. Huria V., Lee K.-L. and Aktan A. E. Nonlinear finite element analysis of RC slab bridge. Journal of Structural Engineering, 1993, 119, No. 1, 88-107.

7. Chowdhury M. R. and Ray J. C. Further considerations for nonlinear finite-element analysis. Journal of Structural Engineering, 1995, 121, No. 9, 1377-1379.

8. Shahrooz B. M., Ho I. K., Aktan A. E., Borst R. D., Blaauwendraad J., Veen C. V. D., Iding R. H. and Miller R. A. Nonlinear finite element analysis of deteriorated RC slab bridge. Journal of Structural Engineering, 1994, 120, No. 2, $422-440$

9. Ho I.-K. and Shahrooz B. M. Finite element modeling of deteriorated R.C. slab bridge: lessons learned and recommendations. Structural Engineering and Mechanics, 1998, 6, No. 3, 259-274.

10. Song H.-W., You D.-W., Byun K.-J. and Maekawa K. Finite element failure analysis of reinforced concrete T-girder bridges. Engineering Structures, 2002, 24, No. 2, 151-162.

11. Plos M. Improved bridge assessment using non-linear finite element analyses. Proceedings of the 1st International Conference on Bridge Maintenance, Safety and Management, Barcelona, 2002, 133-134.

12. Plos M. and Gylltoft K. Bärighetsutredningar av broar $i$ framtiden. Institutionen för konstruktionsteknik. Chalmers tekniska Högskola, 2002, Göteborg Rapport No. 02:6.

13. Plos M. and Gylltoft K. Evaluation of shear capacity of a 
prestressed concrete box girder bridge using non-linear FEM. Structural Engineering International, 2006, 16, No. 3, 213-221.

14. Ayoub A. and Filippou F. C. Nonlinear finite-element analysis of RC shear panels and walls. Journal of Structural Engineering, 1998, 124, No. 3, 298-308.

15. Yамамото T. and Vecchio F. J. Analysis of reinforced concrete shells for transverse shear and torsion. ACI Structural Journal, 2001, 98, No. 2, 191-199.

16. Vecchio F. J. and Sнiм W. Experimental and analytical reexamination of classical beam tests. Journal of Structural Engineering, 2004, 130, No. 3, 460-469.

17. Kettil P., Ródenas J. J., Aguilera Torres C. and Wiberg N.-E. Strength and deformation of arbitrary beam sections using adaptive FEM. Computers and Structures, 2005, 85, No. 1-2, 15-29.

18. Broo H., Plos M., Lundgren K. and Engström B. Simulation of shear-type cracking and failure with non-linear finite element method. Magazine of Concrete Research, 2007, 59, No. 9, 673687.

19. Comité Européen de Normalisation. Eurocode 2: Design of concrete structures. Part 2: Concrete bridges. Design and detailing rules, EN 1992-2. CEN, Brussels, 2005.

20. Cervenka V., Cervenka J. and Pukl R. Safety assessment in fracture analysis of concrete structures. Proceedings of the 6th International Conference on Fracture Mechanics of Concrete and Concrete Stuctures, Catania, 2007, 2, 1043-1049.

21. Hegger J., Sherif A. and Görtz S. Investigation of pre- and postcracking shear behavior of prestressed concrete beams using innovative measuring techniques. ACI Structural Journal, 2004, 101, No. 2, 183-192.

22. VäGVERKET. Allmän teknisk beskrivning för klassningsberäkning av vägbroar (Swedish regulations for structural assessment of road bridges). Vägverket, Borlänge, Sweden, 1998, 78, 110.

23. Vecchio F. J. and Collins M. P. The modified compressionfield theory for reinforced concrete elements subjected to shear. Journal of the American Concrete Institute, 1986, 83, No. 2, 219-231.

24. PANG X.-B. D. and Hsu T. T. C. Behavior of reinforced concrete membrane elements in shear. ACI Structural Journal, 1995, 92, No. 6, 665-679.

25. PANG X.-B. D. and HsU T. T. C. Fixed angle softened truss model for reinforced concrete. ACI Structural Journal, 1996, 93, No. 2, 197-207.

26. Plos M., Gylltoft K., Jeppson J., Carlsson F., ThelandersSON S., ENOCHSSON O. and ELFGREN L. Evaluering av bärförmåga hos broar med hjälp av förfinade analysmetoder Ett samarbetsprojekt mellan LTH, LTU och Chalmers. Institutionen för Konstruktion och Mekanik, Betongbyggnad, 2004, Göteborg Rapport 04:3.
27. Broo H., Lundgren K. and Engström B. Shear and torsion in prestressed hollow core units: finite element analyses of fullscale tests. Structural Concrete, 2007, 8, No. 2, 87-100.

28. Lundgren K., Broo H. and Engström B. Analyses of hollow core floors subjected to shear and torsion. Structural Concrete, 2004, 5, No. 4, 1464-1477.

29. TNO. DIANA Finite Element Analysis User's Manual Release 9. TNO DIANA BV, Delft, the Netherlands, 2004.

30. Collins M. P. and Mitchell D. Prestressed Concrete Structures. Prentice Hall, Englewood Cliffs, New Jersey, 1991.

31. Enochsson O., Puurula A. and Elfgren L. Beräkning av betongbroars bärförmåga: Interaktion mellan tvärkraft, vridmoment och böjmoment $i$ Källösundsbron. Institutionen för Samhällsbyggnad (Assessment of load carrying capacity of concrete bridges - interaction of shear, torsion and bending in the Källösund Bridge), Luleå Tekniska Universitet, Luleå, Sweden, 2004.

32. Plos M. Structural Assessment of the Källösund Bridge Using Finite Element Analysis: Evaluation of the Load Carrying Capacity for ULS. Concrete Structures, Department of Structural and Mechanical Engineering, Chalmers University of Technology, Göteborg, Rapport 04:1, March 2004.

33. BOVERKET. Boverkets handbok om betongkonstruktioner BBK 94. Boverket, Karlskrona, Sweden, 1994.

34. Jeppson J., Carlsson F. and Thelandersson, S. Klassningsberäkning med hjälp av tillförlitlighetsanalys. Avdelningen för konstruktionsteknik, Lunds Tekniska Högskola, Lund, Sweden, 2004, Rapport TVBK-3050.

35. FB_EngINEERING. Konstruktionsberäkningar O497, Bro över Källösund mellan Stenungsön och Källön å väg 160 (Structural assessment and design of strengthening for the Källösund Bridge). FB Engineering AB, Göteborg, Sweden, 2002.

36. International Federation for Structural Concrete (FIB). Structural Concrete. Textbook on Behaviour, Design and Performance: Updated Knowledge of the CEB/FIP Model Code 1990, Vol. 2. fib, Lausanne, Switzerland, 1999.

37. BOVERKET. Boverkets handbok om betongkonstruktioner BBK 04. Boverket, Karlskrona, Sweden, 2004.

38. Comité Européen de Normalisation. Eurocode 2: Design of concrete structures-Part 1: General rules and rules for buildings. vol. EN 1992-1-1, prEN 1992-1-1 Draft for Stage 49 ed. CEN, Brussels, 2004.

39. Jirásex M. Modeling of Localized Inelastic Deformation: Lecture Notes. Czech Technical University, Prague, 2004.

Discussion contributions on this paper should reach the editor by 1 April 2010 